\title{
Piquiá Shells (Caryocar villosum): A Fruit by-Product with Antioxidant and Antiaging Properties in Caenorhabditis elegans
}

\author{
Mariana Roxo $\mathbb{D},{ }^{1}$ Herbenya Peixoto, ${ }^{1}$ Pille Wetterauer $\left(\mathbb{D},{ }^{1}\right.$ Emerson Lima $\mathbb{D},^{2}$ \\ and Michael Wink (i) ${ }^{1}$ \\ ${ }^{1}$ Institute of Pharmacy and Molecular Biotechnology, Heidelberg University, Im Neuenheimer Feld 364, 69120 Heidelberg, Germany \\ ${ }^{2}$ Faculty of Pharmaceutical Sciences, Federal University of Amazonas (UFAM), General Rodrigo 6200, 69077-000 Manaus, Brazil \\ Correspondence should be addressed to Michael Wink; wink@uni-heidelberg.de
}

Received 18 May 2020; Revised 20 July 2020; Accepted 1 August 2020; Published 25 August 2020

Guest Editor: Marina Soković

Copyright (C) 2020 Mariana Roxo et al. This is an open access article distributed under the Creative Commons Attribution License, which permits unrestricted use, distribution, and reproduction in any medium, provided the original work is properly cited.

\begin{abstract}
In a context of rising demand for sustainable antiaging interventions, fruit processing by-products are a promising source of bioactive compounds for the production of antiaging dietary supplements. Piquiá (Caryocar villosum) is a native Amazonian fruit consisting of $65 \%$ nonedible shells. In the present study, the phytochemical profile of a hydroalcoholic extract of piquiá shells $(\mathrm{CV})$ was characterized by LC-MS/MS analysis. Its antioxidant and antiaging activities were investigated using the nematode Caenorhabditis elegans as an in vivo model. CV is mainly composed by hydrolysable tannins and triterpenoid saponins. The extract enhanced stress resistance of wild-type and mutant worms by reducing the intracellular levels of reactive oxygen species (ROS) and by increasing their survival against a lethal dose of the prooxidant juglone. These effects involved the upregulation of sod-3 and downregulation of gst-4 and $h s p-16.2$, studied through the GFP fluorescent reporter intensity and at the transcriptional level by qRT-PCR analysis. CV extended the lifespan of wild-type worms in a DAF-16/FoxO- and SKN1/Nrf-dependent manner. Taken together, our findings indicate piquiá shells as potential candidates for nutraceutical applications. Further studies are needed to validate the relevance of our findings to antiaging interventions in humans.
\end{abstract}

\section{Introduction}

Population aging is leading to an exponential increase in the incidence of age-related health conditions, reflecting extremely high costs for people's welfare and health care systems $[1,2]$. This social context has sparked a global demand for antiaging dietary supplements. In recent years, consumers have increasingly preferred sustainable plant-based supplements, shifting the attention of the food, pharmaceuti$\mathrm{cal}$, and cosmetic industries towards processing of food waste products as an alternative and low-cost source of bioactive compounds with less environmental impact [3]. Within this frame, extracts and compounds isolated from fruit byproducts have shown promising potential $[4,5]$. Although the antiaging potential of fruit by-products is often ascribed to the potent antioxidant activity displayed by their secondary metabolites (e.g., flavonoids, tannins, and other polyphenols), more detailed in vivo studies are needed to support these claims.
Aging results from the complex interplay among genetic, epigenetic, environmental, and stochastic factors [6]. Between the multiple variables involved, oxidative stress has been broadly supported as a considerable contributor to the aging process and thus represents a suitable therapeutic target for the development of novel antiaging interventions [7]. In a more detailed way, as we age, the innate antioxidant network that allows the organism to balance the levels of reactive oxygen species (ROS) from endogenous and exogenous sources is gradually compromised [8]. As a consequence, ROS above physiological levels causes damage to cellular molecules, particularly to proteins, lipids, and DNA (leading to point mutations). The accumulation of oxidative stress-induced damage combined with the decline in repair mechanisms results in mitochondrial dysfunction, loss of proteostasis, and genomic instability, which are shown to contribute to aging itself and to the onset of age-related disorders [9-11]. Therefore, the supplementation of diet with antioxidants, especially those of plant origin, is considered a 
key strategy for the prevention and symptomatic management of age-related health conditions, such as physical frailty, cancer, metabolic syndrome, cardiovascular disorders and neurodegenerative diseases [12-16].

Model systems have been instrumental in understanding the role of oxidative stress in the aging process and in identifying phytochemical antioxidants with antiaging activity [17-19]. Among the model organisms used for drug discovery in aging research, the roundworm Caenorhabditis elegans is considered one of the most costeffective alternative to mammal testing [20]. Indeed, the Database of Ageing-related Drugs (DrugAge) compiles more than 500 compounds with antiaging properties, the majority of which were tested in C. elegans [21]. Some of the characteristics that make the worm an ideal platform for aging research are its small size, short life cycle, large offspring, and a lifespan of around three weeks. Moreover, the high genetic tractability and transparency throughout the whole life allow the visualization of anatomical features, fluorescent dyes, and genetically encoded fluorescent markers [22]. Most importantly, C. elegans genome is fully sequenced, sharing around $42 \%$ orthologues of genes associated with human diseases, and many mutant strains for genes involved in the aging process are readily available [23].

Piquiá (Caryocar villosum (Aubl.) Pers.) is a poorly known native Amazonian fruit consisting of $65 \%$ nonedible shells (external mesocarp) [24]. The pulp, rich in carotenoids, is the most exploited part of the fruit. It is an important part of the Amazonian diet, usually consumed cooked and used for the production of oil for cooking, cosmetic, and medicinal purposes $[25,26]$. The seeds are also edible and a source of oil for cosmetic preparations. Owing to the high oil content of the fruit pulp and seeds, C. villosum is often pointed out as a potential crop for biodiesel production [27]. Piquiá shells, rich in tannins and saponins, are traditionally used for the production of ink, hammock dyes, and soap [28]. Previous works on the chemical composition and bioactivity of piquiá were mainly focused on pulp extracts, revealing high phenolic content, in vitro ROS scavenging ability, antigenotoxicity, and topical anti-inflammatory activity in rat models [29-32]. To our knowledge, only one study evaluated the bioactive potential of piquiá shells, drawing attention to the presence of polyphenols with strong freeradical scavenging capacity in vitro [33]. Since the multiple applications of piquiá pulp generate shells as a by-product, we hypothesized that piquiá shells may represent a sustainable source of antioxidant compounds with potential antiaging properties.

In this study, we characterized the phytochemical composition of a hydroalcoholic extract of piquiá shells (CV) and investigated its antioxidant and antiaging activities in C. elegans, additionally exploring underlying mechanisms of action. The extract was evaluated for its effect on the intracellular accumulation of ROS, protection against lethal oxidative stress, gene expression, and lifespan extension of wild-type and mutant worms for genes involved in stress resistance and longevity in $C$. elegans. CV-mediated changes in gene expression were studied using transgenic strains carrying a GFP reporter for the gene of interest and qRT-PCR analysis.

\section{Material and Methods}

2.1. Plant Material and Extraction Procedure. Ripe fruits of Caryocar villosum were collected at the Amazonian Ducke Forest Reserve, Manaus, Brazil. A hydroalcoholic extraction (8:2 ethanol/water) of the shells was performed at room temperature. The final extract of Caryocar villosum fruit shells was concentrated by rotary evaporation and spray dried, yielding a dark yellow fine powder. For all the experiments, the extract was freshly diluted in sterile water and insoluble particles removed by centrifugation $(10,000 \mathrm{rpm}$ for $5 \mathrm{~min}$ at $4^{\circ} \mathrm{C}$ ).

2.2. Phytochemical Characterization of the Extract-LCMS/MS Analysis. LC-MS/MS analysis was performed on a Finnigan LCQ-Duo ion trap mass spectrometer with an ESI source (ThermoQuest, Hyland Scientific, Stanwood, WA, USA), coupled to a Thermo Scientific Accela HPLC system (MS pump plus, autosampler, and PDA detector plus) with an EC 150/3 Nucleodur 100-3 C18ec column (MachereyNagel, Dueren, Germany). A gradient of water and acetonitrile (ACN) with $0.1 \%$ formic acid each was applied at $30^{\circ} \mathrm{C}$ as follows: $0-15 \% \mathrm{ACN}$ in $15 \mathrm{~min} ; 15 \% \mathrm{ACN}$ for $10 \mathrm{~min}$; $15-35 \% \mathrm{ACN}$ in $20 \mathrm{~min}$; $35 \% \mathrm{ACN}$ for $10 \mathrm{~min}$; $35-50 \%$ $\mathrm{ACN}$ in $20 \mathrm{~min} ; 50-100 \% \mathrm{ACN}$ in $10 \mathrm{~min}$; and $100 \% \mathrm{ACN}$ for $15 \mathrm{~min}$. The flow rate was $0.5 \mathrm{~mL} / \mathrm{min}$. The injection volume was $20 \mu \mathrm{L}$. All samples were measured in the positive and negative mode. The MS was operated with a capillary voltage of $10 \mathrm{~V}$, source temperature of $240^{\circ} \mathrm{C}$, and high purity nitrogen as a sheath and auxiliary gas at a flow rate of 80 and 40 (arbitrary units), respectively. The ions were detected in a mass range of $50-2000 \mathrm{~m} / \mathrm{z}$. Collision energy of $35 \%$ was used in MS/MS for fragmentation. Data acquisitions and analyses were executed by the Xcalibur ${ }^{\mathrm{TM}} 2.0 .7$ software (Thermo Scientific, Waltham, MA, USA).

2.3. In Vitro Antioxidant Activity. The in vitro antioxidant activity of $\mathrm{CV}$ was characterized through the standard assays DPPH (1,1-diphenyl-2-picrydrazyl) and TEAC (trolox equivalent antioxidant capacity) assessed through ABTS (2,2'-azino-bis(3-ethylbenzothiazoline-6-sulfonic acid) decolorization, performed as described in our previous study [34]. Vitamin C (AppliChem GmbH, Darmstadt, Germany) and gallic acid (Sigma-Aldrich $\mathrm{GmbH}$, Steinheim, Germany) were used as positive controls.

\subsection{In Vivo Antioxidant Activity}

2.4.1. C. elegans Strains and Maintenance. All strains used in this study were provided by the Caenorhabditis Genetics Center (CGC, University of Minnesota, Minneapolis, MN, USA), namely N2 (WT), CF1038 [daf-16(mu86)], EU1 [skn1(zu67)], VC475 [hsp-16.2(gk249)], CF1553 [(pAD76) sod3p::GFP + rol-6(su1006)], CL2166 [(pAF15)gst-4p::GFP::NLS], TJ375 [hsp-16.2p::GFP], TJ356 [daf-16p::daf-16a/b::GFP + rol-6(su1006)], LD1 [skn-1b/c::GFP + rol-6(su1006)], and Escherichia coliOP50 (uracil auxotroph). 
The worms were cultured on solid nematode growth medium (NGM), fed on living E. coli OP50, and maintained at $20^{\circ} \mathrm{C}$ [35]. To obtain synchronized populations, the eggs were isolated using a combination of bleaching and sucrose density separation methods and allowed to hatch overnight in M9 buffer [36]. For the experiments, freshly hatched L1 worms were transferred to liquid S-medium inoculated with living E. coli $\mathrm{OP} 50\left(\mathrm{OD}_{600}=1.0\right)$ and treated according to the correspondent assay, in a final volume of $2 \mathrm{~mL} /$ petri dish $(35 \times 10 \mathrm{~mm})$. All assays were performed at $20^{\circ} \mathrm{C}$.

2.4.2. Fluorescence Microscopy and Image Analysis. To analyze the effect of different treatments on the expression of the fluorescent reporter GFP (green fluorescent protein) and the levels of DCF (2',7'-dichlorofluorescein), living worms were mounted onto a glass slide with a drop of $10 \mathrm{mM}$ sodium azide (AppliChem GmbH, Darmstadt, Germany). Fluorescence images $\left(\lambda_{\mathrm{ex}} 488 \mathrm{~nm}\right.$ and $\left.\lambda_{\mathrm{em}} 540\right)$ of at least $30 \mathrm{worms} /$ treatment were acquired at constant exposure time for each experiment, using a Keyence Biorevo BZ-9000 fluorescence microscope (Keyence Deutschland $\mathrm{GmbH}$, Neu-Isenburg, Germany). The fluorescence intensity was densitometrically determined in mean pixels using ImageJ version 1.52 (National Institutes of Health, Bethesda, MD, USA), an open source image processing and analysis software.

2.4.3. Measurement of Intracellular ROS Levels by DCF Assay. N2, CF1038, EU1, and VC475 worms at L1 larval stage were treated with different concentrations of $\mathrm{CV}(50,100$, and $200 \mu \mathrm{g} / \mathrm{mL}$ ), excluding the control group. A positive control of EGCG was included $(25 \mu \mathrm{g} / \mathrm{mL}$ or $50 \mu \mathrm{g} / \mathrm{mL})$. On the first day of adulthood, the worms were incubated for 1 hour at $20^{\circ} \mathrm{C}$ with $20 \mu \mathrm{M}$ DCF-DA $\left(2^{\prime}, 7^{\prime}\right.$-dichlorofluorescein diacetate) (Sigma-Aldrich $\mathrm{GmbH}$, Steinheim, Germany), subsequently washed with M9 buffer to remove residual dye, and analyzed by fluorescence microscopy [37]. ROS levels are expressed as percentage of control (mean \pm SEM) and calculated from the mean pixel intensity of the worm's whole body.

2.4.4. Survival Assay under Juglone-Induced Oxidative Stress. N2, CF1038, EU1, and VC475 worms at L1 larval stage were treated as previously described. On the first day of adulthood, approximately 80 worms per treatment were transferred onto new plates containing freshly inoculated $\mathrm{S}$-medium and $80 \mu \mathrm{M}$ juglone (Sigma-Aldrich $\mathrm{GmbH}$, Steinheim, Germany) [38]. After $24 \mathrm{~h}$, the survivors were counted. Worms with no visible response to a gentle touch stimulus were scored dead. Survival rate is expressed as percentage $($ mean \pm SEM).

\subsubsection{Expression of Stress Resistance-Related Genes}

(1) Subcellular Localization of DAF-16 and SKN-1. TJ356 and LD1 transgenic worms at L4 stage were treated for exactly one hour prior fluorescence microscopy imaging. Each worm was then categorized according to the GFP pattern of expression observed (cytosolic, intermediate, or nuclear) as previously described by our group [39].
(2) Quantification of sod-3, gst-4, and hsp-16.2 Expression under Basal Stress Conditions and/or Juglone-Induced Oxidative Stress. CF1553, CL2166, and TJ375 transgenic worms were treated at L1 stage. After $48 \mathrm{~h}$ of treatment, the adult worms were exposed or not to $20 \mu \mathrm{M}$ of juglone for $24 \mathrm{~h}$ and then analyzed by fluorescence microscopy [37, 40]. Results are shown as percentage of control (mean \pm SEM) calculated from the mean pixel intensity of the worm's tail (sod-3), whole body (gst-4), or head (hsp-16.2).

(3) Quantification of Relative sod-3, gst-4, and hsp-16.2 mRNA Levels: RNA Purification and qRT-PCR. N2 worms at L1 stage were treated as previously mentioned. After $72 \mathrm{~h}$, the worms were collected by gravity, washed three times in $\mathrm{M} 9$ buffer to remove residual E. coli OP50, and flash frozen in liquid nitrogen. Total RNA was isolated and purified using the FastGene RNA Premium Purification Kit (Nippon Genetics Europe GmbH, Dueren, Germany). RNA purity and concentration were assessed by spectrophotometry at 260 and $280 \mathrm{~nm}$. Purity and integrity were further confirmed on an agarose gel. cDNA was synthesized from $1 \mu \mathrm{g}$ of pure RNA using the Nippon FastGene Scriptase II kit. qRT-PCR was performed using PCR Biosystems SyGreen Mix (PCR Biosystems Inc., Wayne, PA, USA) on a Roche LightCycler 96 System (Roche Diagnostics Deutschland GmbH, Mannheim, Germany). Results are presented as fold relative mRNA levels $\left(2^{-\Delta \Delta \mathrm{Ct}}\right)$, calculated from the $\Delta \Delta \mathrm{Ct}$ values normalized to $c d c-42$ as a reference gene. The sequences of the PCR primers used were previously published [41].

2.5. Lifespan. Synchronized N2, CF1038, and EU1 worms were grown in inoculated S-medium until the first day of adulthood. The worms were then separated into treatment groups of approximately 100 individuals. During the egglaying period, the worms were transferred every day to freshly inoculated liquid medium with extract and posteriorly every second day. Worms with internally hatched progeny or extruded gonads were censored. Worms no longer responding to a gentle touch with a platinum wire were scored as dead and excluded from the plates. The results are expressed as percent survival.

\subsection{Feeding Behavior, Development, and Reproduction}

2.6.1. E. coli OP50 Growth and Food Intake. The effect of CV treatment on E. coli OP50 growth and food intake of wildtype worms was assessed through the changes in absorbance at $600 \mathrm{~nm}$ [42]. Briefly, $200 \mu \mathrm{L}$ of freshly E. coli OP50 inoculated S-medium $\left(\mathrm{OD}_{600}=1\right)$ per well was incubated at $20^{\circ} \mathrm{C}$ with or without $200 \mu \mathrm{g} / \mathrm{mL} \mathrm{CV}$ on a 96 -well plate. Measurements were taken every $24 \mathrm{~h}$ for a period of $72 \mathrm{~h}$ using a microplate reader (Tecan, Männedorf, Switzerland). Results are presented as fold E. coli OP50 growth normalized to the absorbance of the respective treatment at day 0 (mean $\pm \mathrm{SEM})$. For the food intake assays, approximately 20 worms (N2 at L1 stage) were added to the inoculated Smedium with or without $200 \mu \mathrm{g} / \mathrm{mL} \mathrm{CV}$, in a final volume of $200 \mu \mathrm{L} /$ well. Due to the observed oxidation of the plant extract, wells containing noninoculated S-medium with or 
without plant extract were used as blank. Measurements followed as described. Results are presented as fold food intake normalized to the absorbance at day 0 (mean \pm SEM).

2.6.2. Body Area. The body area of N2 worms treated from L1 stage with $\mathrm{CV}$ was determined using the worms imaged for DCF assay (Section 2.4.3). Results are expressed as percentage of control (mean \pm SEM).

2.6.3. Brood Size. Synchronized N2 worms at L4 larval stage were placed one by one on individual NGM agar plates. An E. coli OP50 lawn was provided as food source. In the treatment groups, the plant extract was added to the bacterial lawn in a concentration of $200 \mu \mathrm{g} / \mathrm{mL}$. The worms were transferred every day to fresh medium, and after $24 \mathrm{~h}$, the eggs were counted for $5 \mathrm{~d}$ using a dissecting microscope. Brood size results are expressed as number of eggs laid per worm each day (mean \pm SEM).

2.7. Statistical Analyses and Data Interpretation. All graphs were performed using Prism 8 for macOS version 8.2.1 (GraphPad Software, San Diego, CA, USA). For all assays except lifespan, the statistical differences between groups were calculated using one- or two-way ANOVA (brood size assay) followed by Tukey's multiple comparisons test using GraphPad Prism. Lifespan assays were analyzed by Kaplan-Meier followed by the log-rank test using IBM SPSS Statistics for Macintosh version 25.0 (IBM Corp., Armonk, NY, USA).

\section{Results and Discussion}

3.1. Phytochemical Composition of $C V$. The phytochemical composition of CV was analyzed by LC-MS/MS (Figure 1). A total of 43 peaks were characterized and 33 compounds were tentatively identified by their molecular mass, fragmentation pattern, and absorption based on literature data (Tables 1 and 2). Overall, CV contains polyphenols belonging to the major group of the hydrolysable tannins (including ellagi- and gallotannins) and triterpenoid saponins. Phenolic compounds showed strong absorption and were better characterized in the negative mode, while for saponins, no absorption was detected, and the positive ion mode provided more detailed structural information.

Gallic acid, ellagic acid, and respective derivatives were previously reported as major phenolic compounds of $C$. villosum extracts from both shells and pulp [33, 43]. Peaks 2-5, 12, 18, and 22 correspond to compounds already reported for C. villosum. To our knowledge, the tentatively identified hydrolysable tannins corresponding to the peaks $1,8,9,13$, $14,15,16,17,19,20,23$, and 26 are reported here for the first time in Caryocar spp. Peak 1 with $m / z 355\left[\mathrm{M}-\mathrm{H}^{+}\right]^{-}$, and the fragment ion with $m / z 337\left[\mathrm{M}-\mathrm{H}^{+}-\mathrm{H}_{2} \mathrm{O}\right]^{-}$was tentatively identified as chebulic acid [44]. Peak 8 with $\mathrm{m} / z 469$ [M$\left.\mathrm{H}^{+}\right]^{-}$produced the fragment ion with $m / z$ $425\left[\mathrm{M}-\mathrm{H}^{+}\right.$$\left.\mathrm{CO}_{2}\right]^{-}$as described by Wyrepkowski et al. [45] for valoneic acid dilactone. Peaks $\mathbf{9}$ and $\mathbf{1 5}$ probably correspond to galloyl-valoneoyl-glucoside isomers. In the negative mode, they show a $m / z$ of $801\left[\mathrm{M}-\mathrm{H}^{+}\right]^{-}$with the major fragment ion with $m / z 757\left[\mathrm{M}-\mathrm{H}^{+}-\mathrm{CO}_{2}\right]^{-}$. This ion gives further frag- ment ions with $m / z 633,613$, and 301 as reported previously for galloyl-decarboxy-valeoyl-glucoside [46]. Peaks 13, 20, and 26, exhibiting the same quasimolecular ion with $\mathrm{m} / \mathrm{z}$ $951\left[\mathrm{M}-\mathrm{H}^{+}\right]^{-}$, same $\lambda_{\max }$ at $171 \mathrm{~nm}$, and same fragmentation pattern, seem to be isomers of the same substance. Due to the

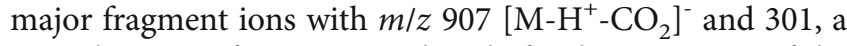
typical MS/MS fragment produced after lactonization of the hexahydroxydiphenoyl (HHDP) group into ellagic acid, they were tentatively assigned to HHDP-valoneoyl-glucoside, as proposed by Yisimayili et al. [47]. According to the same authors, the peak 14, also with $m / z 951\left[\mathrm{M}-\mathrm{H}^{+}\right]^{-}$but different absorption and fragmentation, was identified as galloylHHDP-DHHDP-hexoside. Peak 23 has with $\mathrm{m} / z 907$ [M$\left.\mathrm{H}^{+}\right]^{-}$the same ion mass as the major fragment of HHDPvaloneoyl-glucoside, and also, its fragmentation pattern is very similar. Therefore, this compound was tentatively identified as HHDP-decarboxy-valoneoyl-glucoside. Peak 16 with $m / z 925\left[\mathrm{M}-\mathrm{H}^{+}\right]^{-}$and a major fragment ion with $\mathrm{m} / z$ 301 show the same fragmentation pattern as described for phyllanthusiin C by Catarino et al. [48]. Peak 17 with $\mathrm{m} / z$ $969\left[\mathrm{M}-\mathrm{H}^{+}\right]^{-}$and major fragment ions with $\mathrm{m} / z 925[\mathrm{M}-$ $\left.\mathrm{H}^{+}-\mathrm{CO}_{2}\right]^{-}, 633$, and 301 were tentatively identified as phyllanthusiin B by comparison with the same authors. Peak 19

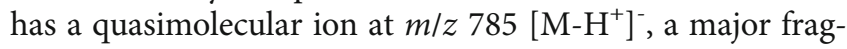
ment ion with $m / z 301$ and another typical fragment ion with

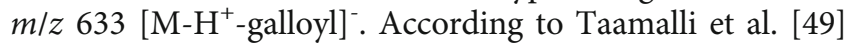
and Yisimayili et al. [47], this fragmentation pattern corresponds to digalloyl-HHDP-glucose.

The tentatively identified triterpenoid saponins have been already described for stem bark and fruits of C. villosum and C. glabrum [50-52]. The source fragmentation data in Table 2 corresponds to the previously reported fragmentation patterns.

3.2. In Vitro Antioxidant Activity. DPPH and ABTS assays were performed to characterize the in vitro antioxidant activity of CV (Table 3). The extract showed a strong radical scavenging activity, comparable to that of ascorbic acid, a well-known potent antioxidant used as a positive control in our study. Gallic acid, previously reported as a major compound of $C$. villosum extracts and also identified in the extract of the present study, revealed the highest radical scavenging capacity in both assays. These results, although without direct biological significance, may serve as comparative values for further studies on the antioxidant activity of Caryocar spp. extracts.

3.3. In Vivo Antioxidant Activity-C. elegans. DAF-16/FoxO and SKN-1/Nrf are key transcription factors in the regulation of stress resistance, protein homeostasis, and lifespan in C. elegans [55]. The activity of these transcription factors is controlled in parallel but independently by the insulin/IGF-1 pathway (IIS), an evolutionarily conserved pathway that regulates aging from worms to mammals. Under favorable conditions, DAF-16 and SKN-1 are inhibited by the same IIS kinases (SGK-1 and AKT-1/2) through phosphorylation and cytoplasmic retention [19, 56]. Upon different types of stress, reduced IIS signaling releases the inhibition leading to nuclear translocation 


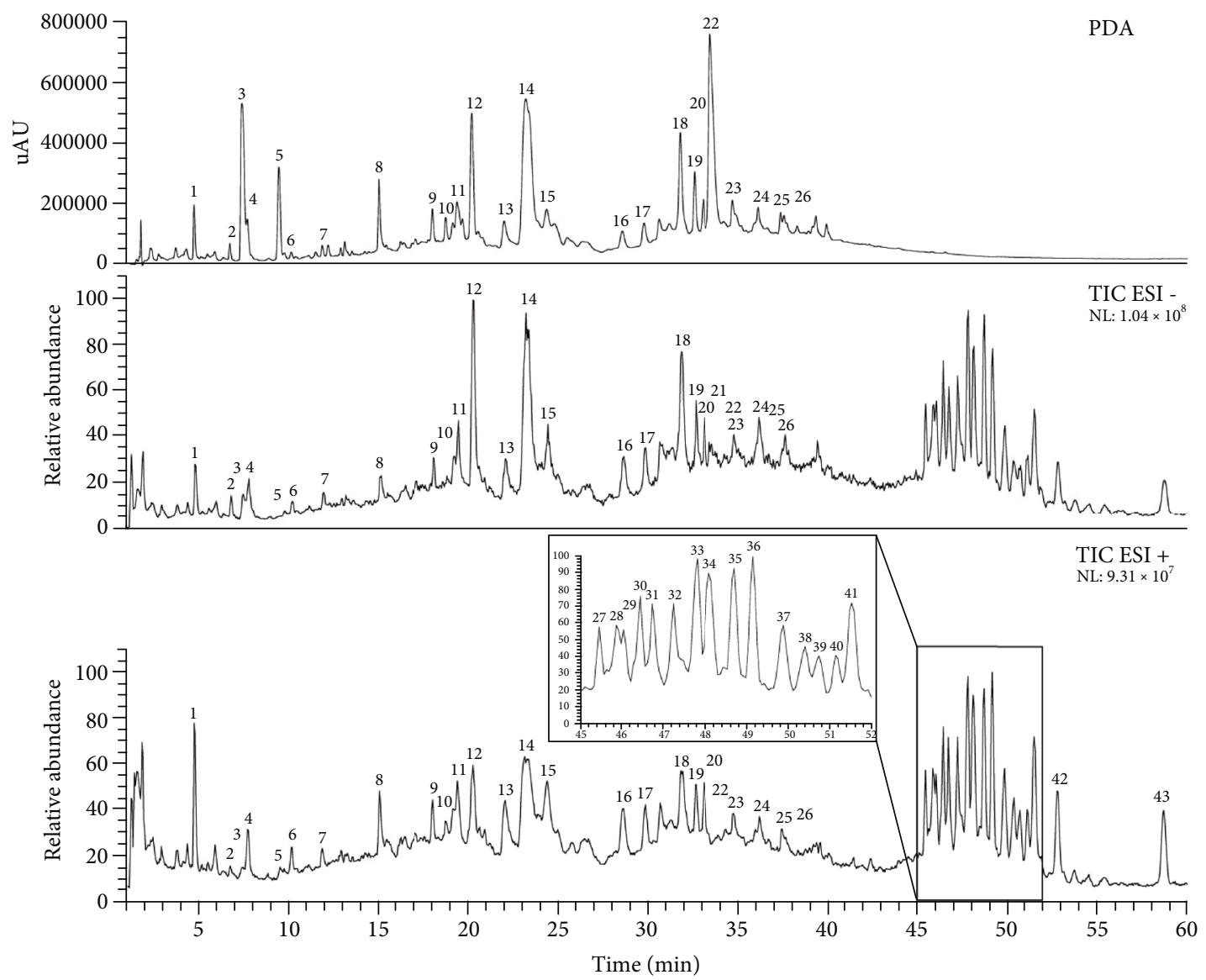

FIgURE 1: Chromatogram (PDA) and total ion current (TIC) of the hydroalcoholic extract of Caryocar villosum fruit shells obtained by LCMS/MS in negative (ESI -) and positive (ESI +) mode. Peak numbers correspond to the tentatively identified compounds presented in Tables 1 and 2 (NL: normative level).

and consequent transcriptional activation or suppression of stress-response genes. Among others, DAF-16 directly regulates the transcription of sod-3, coding for the phase I antioxidant enzyme superoxide dismutase 3 (SOD-3), and coregulates with the heat-shock factor 1 (HSF-1) the expression of $h s p-16.2$, coding for the heat-shock protein 16.2 (HSP-16.2) [57, 58]. SKN-1 is mainly involved in the regulation of phase II detoxification genes, such as gst-4, coding for glutathioneS-transferase 4 (GST-4) [56].

In the present study, we initially tested the antioxidant activity of $\mathrm{CV}$ by evaluating its effect on the in vivo scavenging of ROS and resistance against lethal oxidative stress. The mechanisms of action involved in the antioxidant activity of $\mathrm{CV}$ were further explored by analyzing the effect of the extract on the activation of DAF-16 and SKN-1 and respective downstream targets-sod-3, gst-4, and hsp-16.2.

3.3.1. ROS Levels and Survival against Juglone-Induced Oxidative Stress. In a first set of experiments, we assessed the effect of CV extract on the basal levels of ROS in wildtype worms (N2) using the oxidation-sensitive fluorescent probe DCF [59]. The extract was able to significantly reduce the intracellular ROS accumulation at all concentrations tested in a dose-dependent manner (Figure 2(a)). At the maximum concentration tested $(200 \mu \mathrm{g} / \mathrm{mL}), \mathrm{CV}$ reduced the levels of ROS by $58.74 \pm 1.76 \%$ in comparison to the untreated control $(p<0.0001)$.

To elucidate the role of DAF-16 and SKN-1 in the observed activity, knock-out mutants for these transcription factors were employed (CF1038 and EU1, respectively). Although to a lesser extent, CV also significantly reduced the levels of ROS in both mutants (Figures 2(b) and 2(c)). For the $s k n-1$ mutant, CV displays a U-shaped doseresponse curve, with the highest ROS scavenging activity at $100 \mu \mathrm{g} / \mathrm{mL}$. This result might be indicative of a prooxidant effect of the extract at higher doses as a direct consequence of the absence of important detoxification genes. Additionally, in the hsp-16.2 mutant (VC475), CV decreased the accumulation of ROS with slight differences between concentrations tested (Figure 2(d)). Representative fluorescence images of the living worms analyzed for the quantification of ROS can be found in the supplementary information (Figure S1).

Yamaguchi et al. [33] also demonstrated the ability of a piquiá shells extract to scavenge free radicals in vitro. In a cell-based antioxidant assay, the extract was able to inhibit oxidation reducing by almost $100 \%$ the ROS levels, and in a model of LPS-stimulated macrophages, it nearly suppressed the production of nitric oxide, a free radical that acts as proinflammatory mediator. 
TABLE 1: Tentative identification of polyphenols from a hydroalcoholic extract of Caryocar villosum fruit shells by LC-MS/MS analysis (ESI -).

\begin{tabular}{|c|c|c|c|c|c|c|c|}
\hline Peak $^{\mathrm{a}}$ & Tentative identification & $\begin{array}{c}R_{\mathrm{t}} \\
(\min )^{\mathrm{b}}\end{array}$ & $\begin{array}{l}\lambda_{\max } \\
(\mathrm{nm})\end{array}$ & $\begin{array}{l}{\left[\mathrm{M}-\mathrm{H}^{+}\right]^{-}} \\
\quad(m / z)\end{array}$ & MS/MS fragments $(m / z)^{c}$ & $\mathrm{MS}^{3}$ fragments $(m / z)^{\mathrm{d}}$ & Reference \\
\hline 1 & Chebulic acid & 4.8 & 284 & 355 & 337 & & {$[44]$} \\
\hline 2 & Monogalloyl hexoside & 6.8 & 278 & 331 & $271,241,211,193,169,125$ & & [43] \\
\hline 3 & Gallic acid & 7.5 & 264 & 169 & 125 & & Standard \\
\hline 4 & HHDP-hexoside & 7.8 & 272 & 481 & $463,319,301,275$ & $445,301,275$ & [43] \\
\hline 5 & Digalloyl hexoside & 9.5 & 280 & 483 & $331,313,271,241,169$ & $313,271,241,211,169,125$ & [43] \\
\hline 6 & Unknown & 10.2 & 269 & 355 & $337,311,293,267,205$ & $293,267,223,205,179,149$ & - \\
\hline 7 & Unknown & 12.0 & 273 & 353 & $334,308,265,221,177$ & & - \\
\hline 8 & Valoneic acid dilactone & 15.1 & $\begin{array}{l}254 \\
373\end{array}$ & 469 & 425 & $425,407,301,300,299$ & [45] \\
\hline 9 & $\begin{array}{l}\text { Galloyl-valoneoyl- } \\
\text { glucoside isomer }\end{array}$ & 18.1 & 266 & 801 & $757,756,633,631,613$ & & {$[46]$} \\
\hline 10 & $\begin{array}{l}\text { Brevifolin carboxylic } \\
\text { acid }\end{array}$ & 18.8 & $\begin{array}{l}276 ; \\
353\end{array}$ & 291 & 247 & & {$[53]$} \\
\hline 11 & Unknown & 19.5 & 273 & 1083 & 935 & & - \\
\hline 12 & $\begin{array}{l}\text { Galloyl-HHDP-hexoside } \\
\text { (corilagin) }\end{array}$ & 20.3 & 263 & 633 & $615,481,463,419,301,275$ & & {$[43]$} \\
\hline 13 & $\begin{array}{l}\text { HHDP-valoneoyl- } \\
\text { glucoside isomer }\end{array}$ & 22.1 & 271 & 951 & $933,907,799,737,301$ & $\begin{array}{c}863,755,737,633,605,453 \\
435,301\end{array}$ & {$[47]$} \\
\hline 14 & $\begin{array}{l}\text { Galloyl-HHDP- } \\
\text { DHHDP-hexoside }\end{array}$ & 23.2 & $\begin{array}{l}258 \\
363\end{array}$ & 951 & $933,915,613,301$ & & {$[47]$} \\
\hline 15 & $\begin{array}{l}\text { Galloyl-valoneoyl- } \\
\text { glucoside isomer }\end{array}$ & 24.4 & 265 & 801 & 757 & $\begin{array}{c}633,632,631,613,605,603 \\
587,463,425,301\end{array}$ & {$[46]$} \\
\hline 16 & Phyllanthusiin C & 28.7 & 273 & 925 & $\begin{array}{c}907,633,615,605,453,435,301 \\
273\end{array}$ & & {$[48]$} \\
\hline 17 & Phyllanthusiin B & 29.9 & 272 & 969 & $\begin{array}{c}951,925,907,895,851,755,633 \\
301\end{array}$ & & {$[48]$} \\
\hline 18 & Chebulagic acid & 31.9 & 272 & 953 & $\begin{array}{c}935,909,801,783,757,633,481 \\
463,319,301,275\end{array}$ & & {$[44,54]$} \\
\hline 19 & $\begin{array}{l}\text { Digalloyl-HHDP- } \\
\text { glucose }\end{array}$ & 32.7 & $\begin{array}{l}258 \\
360\end{array}$ & 785 & $\begin{array}{c}633,615,589,463,419,301,275 \\
249\end{array}$ & & {$[47,49]$} \\
\hline 20 & $\begin{array}{l}\text { HHDP-valoneoyl- } \\
\text { glucoside isomer }\end{array}$ & 33.2 & 271 & 951 & $933,907,836,737,435,301$ & & {$[47]$} \\
\hline 21 & Unknown & 33.4 & $\begin{array}{l}252 \\
362\end{array}$ & 894 & $\begin{array}{c}875,806,725,653,506,447,300 \\
293\end{array}$ & & - \\
\hline 22 & Ellagic acid & 33.6 & $\begin{array}{l}252 \\
364\end{array}$ & 301 & $301,257,229,185$ & & {$[43]$} \\
\hline 23 & $\begin{array}{l}\text { HDDP-decarboxy- } \\
\text { valoneoyl-glucoside }\end{array}$ & 34.8 & $\begin{array}{l}272 \\
353\end{array}$ & 907 & $\begin{array}{c}755,737,633,605,587,453,435 \\
291,273\end{array}$ & & - \\
\hline 24 & Unknown & 36.2 & 273 & 939 & 785 & & - \\
\hline 25 & Unknown & 37.5 & 272 & 917 & $747,721,615,445,301$ & & - \\
\hline 26 & $\begin{array}{l}\text { HHDP-valoneoyl- } \\
\text { glucoside isomer }\end{array}$ & 37.7 & 271 & 951 & $\begin{array}{c}907,737,649,615,587,479,435 \\
335,301\end{array}$ & & {$[47]$} \\
\hline
\end{tabular}

${ }^{a}$ Peak numbers refer to the peaks presented in Figure $1 .{ }^{\mathrm{b}} R_{\mathrm{t}}$ : retention time in TIC. ${ }^{\mathrm{c}}$ The ion shown in bold face was the precursor for MS ${ }^{3}$ fragmentation. ${ }^{\mathrm{d}}$ The $\mathrm{MS}^{3}$ spectra were obtained by MS/MS of ions of the source fragmentation. HHDP: hexahydroxydiphenoyl; DHHDP: dehydroxyhexahydroxydiphenoyl.

In order to investigate whether CV confers resistance against acute oxidative stress, survival assays under a lethal dose of the prooxidant juglone were performed using the strains previously tested. Juglone, a naphthoquinone isolated from walnut tree (Juglans regia L.), is commonly used as an oxidative stress inducer in C. elegans $[60,61]$. Depending on the concentration applied, it can induce mild to lethal oxi- dative stress via a redox cycling mechanism. Based on previous investigations carried out in our laboratory, we selected a dose of $80 \mu \mathrm{M}$ juglone to induce lethal oxidative stress [62]. Wild-type worms treated with $200 \mu \mathrm{g} / \mathrm{mL} \mathrm{CV}$ were the most resistant to $80 \mu \mathrm{M}$ juglone (Figure 3(a)), with a survival rate of $57 \pm 7.49 \%$ in comparison to $22.20 \pm 2.14 \%$ in the juglone group $(p<0.0001)$. As expected, the daf-16 mutant, which 
TABLE 2: Tentative identification of triterpenoid saponins from a hydroalcoholic extract of Caryocar villosum fruit shells by LC-MS/MS analysis $(\mathrm{ESI}+)$.

\begin{tabular}{|c|c|c|c|c|c|c|}
\hline Peak $^{\mathrm{a}}$ & Tentative identification & $\begin{array}{c}R_{\mathrm{t}} \\
(\min )^{\mathrm{b}}\end{array}$ & $\begin{array}{c}{\left[\mathrm{M}+\mathrm{H}^{+}\right]^{+}} \\
(m / z)\end{array}$ & $\begin{array}{c}\text { Source } \\
\text { fragmentation }\end{array}$ & MS/MS fragments of $\left[\mathrm{M}+\mathrm{H}^{+}\right]^{+}$ & Reference \\
\hline 27 & Caryocaroside III-16 & 45.5 & 1431 & $\begin{array}{c}1269,1137,975 \\
813,651\end{array}$ & $1431,1412,1142,957,929,826,453$ & {$[50]$} \\
\hline 28 & Caryocaroside III-14 & 45.9 & 1269 & $\begin{array}{c}1107,975,813 \\
651\end{array}$ & $1251,1240,1074,743$ & {$[50]$} \\
\hline 29 & Caryocaroside III-13 & 46.1 & 1137 & $975,813,651$ & $1138,939,691,530$ & {$[50]$} \\
\hline 30 & Caryocaroside III-12 & 46.4 & 1107 & $945,813,651$ & $704,404,321$ & {$[50]$} \\
\hline 31 & Caryocaroside III-2/III-3 & 46.7 & 975 & 813,651 & $956,842,806,738,674$ & {$[51]$} \\
\hline 32 & Caryocaroside II-16 & 47.2 & 1415 & $\begin{array}{c}1253,1121,959 \\
797\end{array}$ & $\begin{array}{c}1418,1404,1370,1356,1312,1275,1235 \\
1021,727\end{array}$ & {$[50]$} \\
\hline 33 & Unknown caryocaroside & 47.8 & 1253 & $1091,959,797$ & 1253,1009 & - \\
\hline 34 & Caryocaroside II-13 & 48.1 & 1121 & $959,797,635$ & 1122,583 & {$[50]$} \\
\hline 35 & Caryocaroside II-12 & 48.7 & 1091 & $929,797,635$ & 1074,833 & {$[50]$} \\
\hline 36 & Caryocaroside II-2/II-3 & 49.2 & 959 & 797,635 & $930,856,831,734$ & {$[51]$} \\
\hline 37 & Caryocaroside IV-21 & 49.9 & 1429 & $\begin{array}{l}1267,1135,973 \\
811,649\end{array}$ & $\begin{array}{c}1427,1414,1376,1370,1326,1267,1134 \\
1115,1069,869\end{array}$ & {$[50]$} \\
\hline 38 & Unknown caryocaroside & 50.4 & 1135 & $973,811,649$ & & - \\
\hline 39 & Unknown caryocaroside & 50.7 & 1267 & $\begin{array}{l}1105,973,811 \\
649\end{array}$ & $1239,1071,1000$ & - \\
\hline 40 & Unknown caryocaroside & 51.2 & 1135 & $973,797,635$ & & - \\
\hline 41 & Caryocaroside IV-17 & 51.5 & 1105 & $943,811,649$ & & {$[50]$} \\
\hline 42 & $\begin{array}{l}\text { Caryocaroside II-9/IV-9/II- } \\
\text { 11/IV-11/III-22 }\end{array}$ & 52.9 & 973 & 811 & $974,928,852,786,762,657$ & {$[51,52]$} \\
\hline 43 & Caryocaroside IV-7 & 58.8 & 811 & 649 & & {$[52]$} \\
\hline
\end{tabular}

${ }^{a}$ Peak numbers refer to the peaks presented in Figure $1 .{ }^{\mathrm{b}} R_{\mathrm{t}}$ : retention time in TIC.

TABle 3: In vitro antioxidant activity of Caryocar villosum shells extract $(\mathrm{CV})$.

\begin{tabular}{lcc}
\hline Sample & $\begin{array}{c}\mathrm{DPPH} \\
\mathrm{IC}_{50}(\mu \mathrm{g} / \mathrm{mL})\end{array}$ & $\begin{array}{c}\text { TEAC/ABTS } \\
(\mathrm{mM} \text { trolox/mg sample })\end{array}$ \\
\hline CV & $3.01 \pm 0.10$ & $4.76 \pm 0.14$ \\
Ascorbic acid & $3.06 \pm 0.14$ & $5.73 \pm 0.42$ \\
Gallic acid & $1.12 \pm 0.05$ & $13.27 \pm 0.82$ \\
\hline
\end{tabular}

DPPH: 2,2-diphenyl-1-picrylhydrazyl; TEAC: trolox equivalent antioxidant capacity; ABTS: 2,2'-azino-bis(3-ethylbenzothiazoline-6-sulfonic acid).

previously exhibited higher levels of ROS, showed higher sensitivity to oxidative stress (Figure 3(b)). For the $s k n-1$ mutant, the highest survival rate corresponded to the treatment group with the highest levels of ROS (Figure 3(c)). This result shows that the mild prooxidant effect of $\mathrm{CV}$ at $200 \mu \mathrm{g} / \mathrm{mL}$ positively mediated the response of $s k n-1$ mutants to lethal oxidative stress, suggesting a hormetic doseresponse $[63,64]$. Similar results were reported for other tannin-rich plant extract [65] and several dietary antioxidants, such as caffeine and related methylxanthines [41], tomatidin [66], and quercetin [67]. Mutant worms for hsp16.2 showed increased resistance to oxidative stress only when treated with $200 \mu \mathrm{g} / \mathrm{mL} \mathrm{CV} \mathrm{(Figure} \mathrm{3(d)).} \mathrm{Taken}$ together, our results suggest that the enhanced stress resis- tance elicited by CV treatment is, apparently, not strictly dependent on daf-16, skn-1, and $h s p-16.2$. However, if taken quantitatively, these results might also allow us to conclude that the absence of DAF-16 signaling negatively impacts the antioxidant capacity of $\mathrm{CV}$, since the daf-16 mutant showed overall higher ROS levels and lower survival rates in comparison to the wild-type worms.

3.3.2. Expression of Stress Resistance-Related Genes. Plant extracts rich in polyphenols were previously found to exert antioxidant and lifespan-promoting effects in C. elegans by inducing the transcriptional activity of DAF-16 and SKN-1, thus modulating the expression of genes related to stress resistance and longevity $[37,68,69]$. To clarify which genes are modulated by $\mathrm{CV}$ to enhance oxidative stress resistance in C. elegans, we initially analyzed its effect on the activation of DAF-16 and SKN-1. The effect of different concentrations of CV on the subcellular localization patterns of both transcription factors was determined using the transgenic strains TJ356 and LD1 carrying a translational GFP reporter for DAF-16 and SKN-1, respectively (Figures 4(a) and 4(b)). CV treatment induced the translocation of DAF-16 to the nucleus (Figure 4(c)) but failed to activate SKN-1 (Figure 4(d)). DAF-16 nuclear localization was induced by $100 \mu \mathrm{g} / \mathrm{mL}$ in $32.51 \pm 12.40 \%$ of the worms, in comparison to the untreated control $(p<0.05)$. 


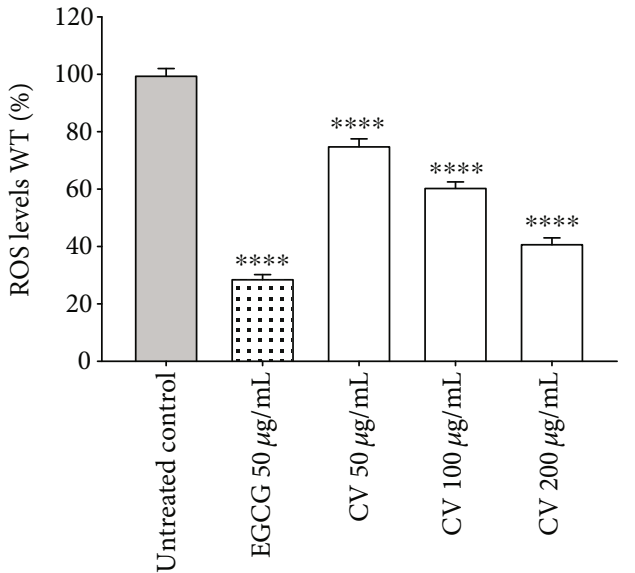

(a)

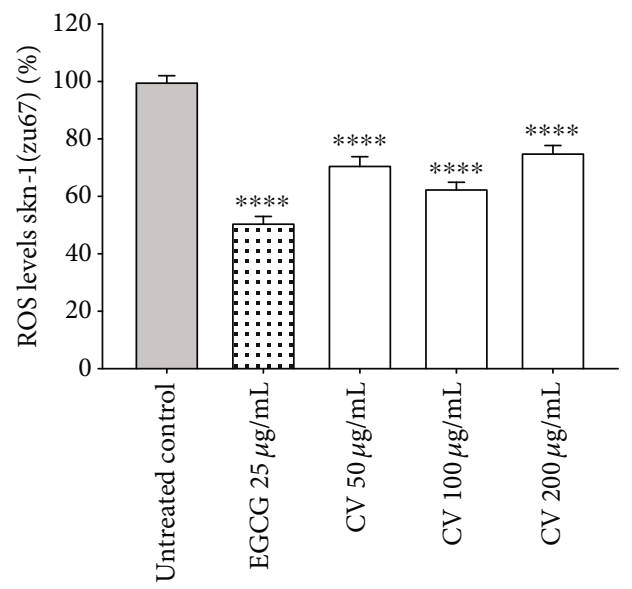

(c)

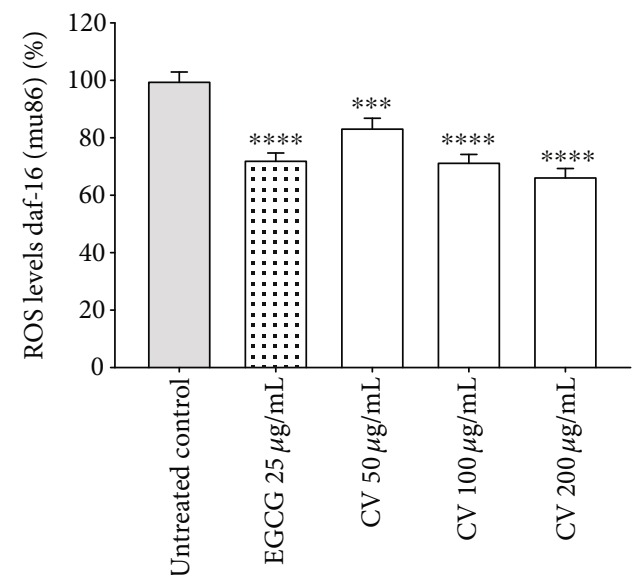

(b)

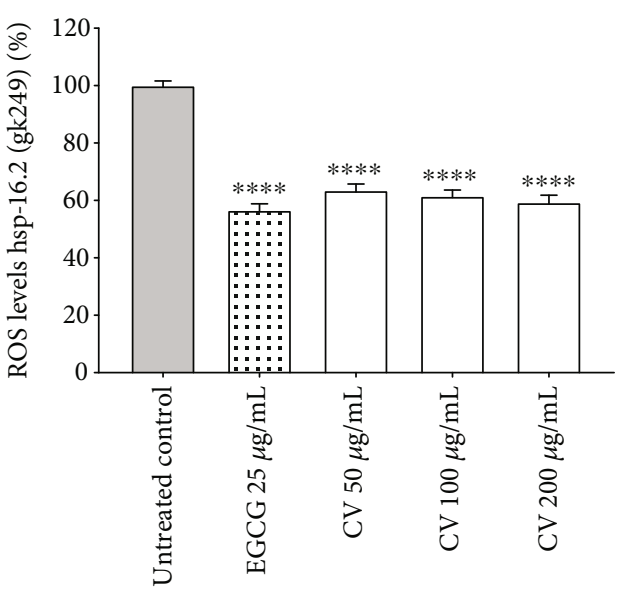

(d)

FIGURE 2: Intracellular ROS accumulation under basal stress conditions of wild-type (a) and mutant worms for daf-16 (b), skn-1 (c), and hsp16.2 (d) treated with Caryocar villosum fruit shells (CV). The results are expressed as mean percentage of control \pm SEM from at least three independent experiments, calculated from DCF intensity of the worm's whole body $(* * * * p<0.0001$, compared to the untreated control).

The expression levels of DAF-16 and SKN-1 target genes, sod-3, gst-4, and $h s p-16.2$, were subsequently determined using strains carrying a GFP reporter coupled to the promotor of the respective gene and through qRT-PCR analysis. Initially, we employed the transgenic strain CF1535 to investigate the expression of sod-3::GFP under basal stress conditions and under mild oxidative stress, induced by a dose of $20 \mu \mathrm{M}$ juglone. This concentration of juglone was previously shown to induce the expression of stress resistance-related genes without compromising the vital functions of the worms $[62,70]$.

Representative fluorescence images of the living worms analyzed for the quantification of sod-3 can be found in the supplementary information (Figures S2 and S3). Under basal stress conditions, $100 \mu \mathrm{g} / \mathrm{mL} \mathrm{CV}$ significantly increased the fluorescence intensity by $13.2 \pm 1.83 \%$, in comparison to the untreated control $(p<0.0001)$ (Figure 5(a)). In contrast, at $200 \mu \mathrm{g} / \mathrm{mL}$, we could observe a significant decrease in GFP intensity. A mild dose of $20 \mu \mathrm{M}$ juglone resulted in a more pronounced induction of sod-3::GFP at all CV concentrations tested (Figure 5(b)). A maximum upregulation of $24.3 \pm 3.74 \%$ occurred at $100 \mu \mathrm{g} / \mathrm{mL}$, in comparison to the juglone treatment $(p<0.0001)$.

The expression of sod-3 was also investigated at the transcriptional level through qRT-PCR analysis. The mRNA levels of sod-3 under basal stress conditions followed the same pattern as the GFP intensity (Figure 5(c)). As expected, in worms treated with CV $100 \mu \mathrm{g} / \mathrm{mL}$, the relative mRNA levels were higher than in the untreated control. This result, combined with the GFP intensity and the DAF-16 localization pattern previously observed, suggests that at $100 \mu \mathrm{g} / \mathrm{mL} \mathrm{CV}$ induces the translocation of DAF-16 to the nucleus resulting in upregulation of sod-3, its target gene.

Treatment with $200 \mu \mathrm{g} / \mathrm{mL} \mathrm{CV}$ resulted in a maximum reduction of ROS levels by $58.74 \pm 1.76 \%$ (Figure 2(a)); however, at this concentration, the expression levels of sod-3 were reduced. This result is apparently contradictory, because low levels of ROS are usually correlated with higher expression levels of the antioxidant enzyme sod-3 [37, 71]. Despite that, a similar effect was also reported for other phytochemical and synthetic antioxidants. Quercetin and resveratrol were shown to protect $C$. elegans from oxidative stress and to 


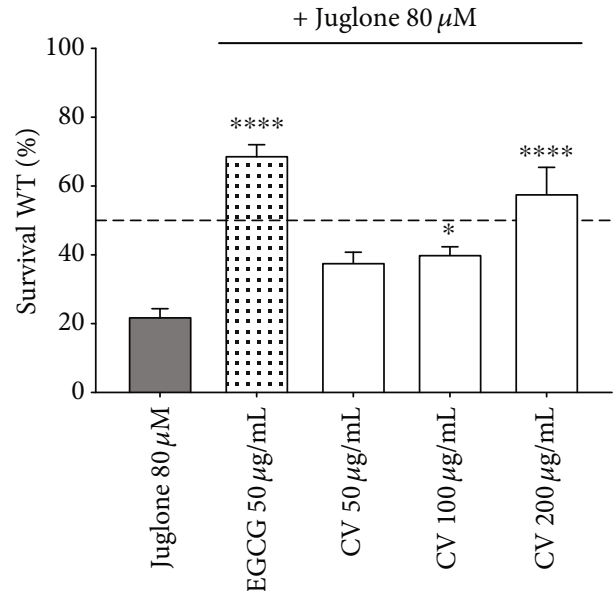

(a)

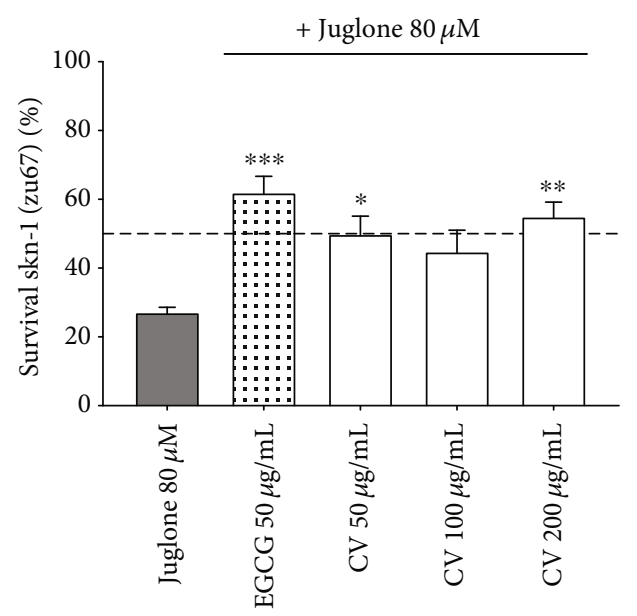

(c)

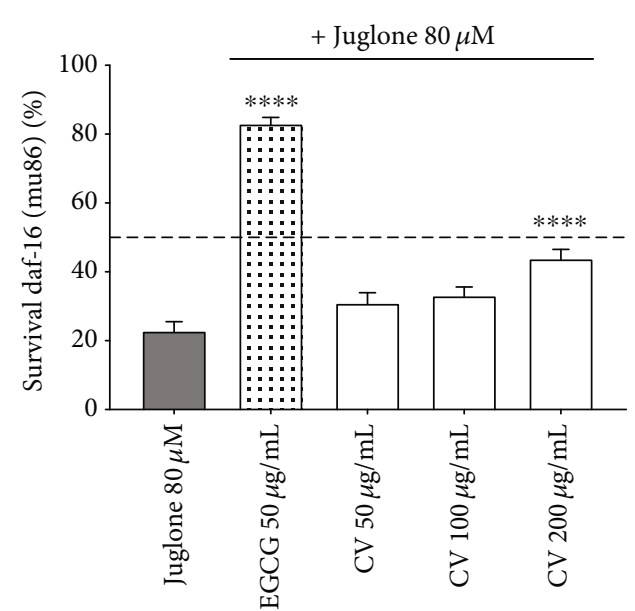

(b)

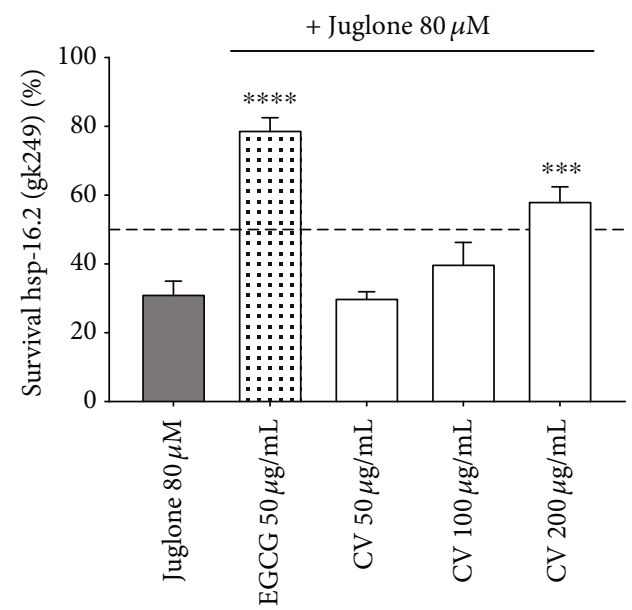

(d)

FIgURe 3: Effect of Caryocar villosum fruit shells (CV) on the survival rate of wild-type (N2) and mutant worms for daf-16 (b), skn-1 (c), and $h s p-16.2(\mathrm{~d})$, exposed to $80 \mu \mathrm{M}$ juglone to induce lethal oxidative stress. Survival rate is expressed as mean percentage survival \pm SEM of at least four independent experiments $(* p<0.05, * * p<0.01$, and $* * * p<0.001$, compared to juglone).

reduce the intracellular levels of ROS, although both compounds reduced the expression of sod-3 [72, 73]. The standard antioxidants ascorbic acid, butylated hydroxyanisole (BHA), and sodium ascorbate were also reported to reduce ROS levels in C. elegans simultaneously reducing the expression of sod-3 [74]. According to the authors, the sharp reduction in the levels of ROS induced by potent antioxidants leads to the absence of cellular oxidative burden, resulting in the repression of sod-3 expression. Most probably, this argument explains the results obtained in this study for $200 \mu \mathrm{g} / \mathrm{mL} \mathrm{CV}$. Our findings suggest that $200 \mu \mathrm{g} / \mathrm{mL}$ is the threshold antioxidant concentration from which $\mathrm{CV}$ ceases to induce the expression of sod-3.

Under oxidative stress, an inverse correlation between mRNA levels and sod-3::GFP intensity was observed (Figure 5(d)). The relative levels of mRNA were measured in wild-type worms, and the GFP intensity was determined using a mutant strain carrying a transcriptional reporter. In C. elegans research, the transcriptional fusion approach is often used alternatively to qRT-PCR to investigate changes in gene expression. However, transcriptional reporters may lack potential regulatory elements located beyond the $5^{\prime}$ end or at the $3^{\prime}$-unstranslated region, resulting in misleading patterns of gene expression [75]. Reasoning from this fact, the effect of CV treatment on the expression of sod-3 might be better represented by the GRT-PCR data rather than the GFP intensity. In any case, these results deserve further attention.

Considering that gst-4 and $h s p-16.2$ are stress inducible genes, we tested the effect of CV on the expression levels of these genes only under mild oxidative stress. A dose of $20 \mu \mathrm{M}$ juglone was previously reported by our and other research groups as a mild oxidative stress stimulus, which is able to strongly induce the expression of gst-4::GFP and hsp-16.2::GFP [37, 39, 70, 73]. Accordingly, in this study, worms under juglone-induced stress showed strong GFP intensity, which was almost undetectable in the untreated worms (Figure 6(a)). CV treatment reduced the fluorescence intensity of both gst-4::GFP (CL2166) and hsp-16.2::GFP (TJ375) in a dose-dependent manner (Figures 6(c) and 6(d)). At $200 \mu \mathrm{g} / \mathrm{mL}, \mathrm{CV}$ reduced the expression of gst4::GFP by $69.95 \pm 1.31 \%$ and of $h s p-16.2::$ GFP by $39.40 \pm$ 


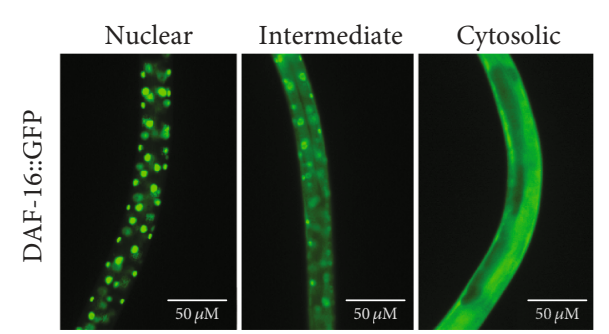

(a)

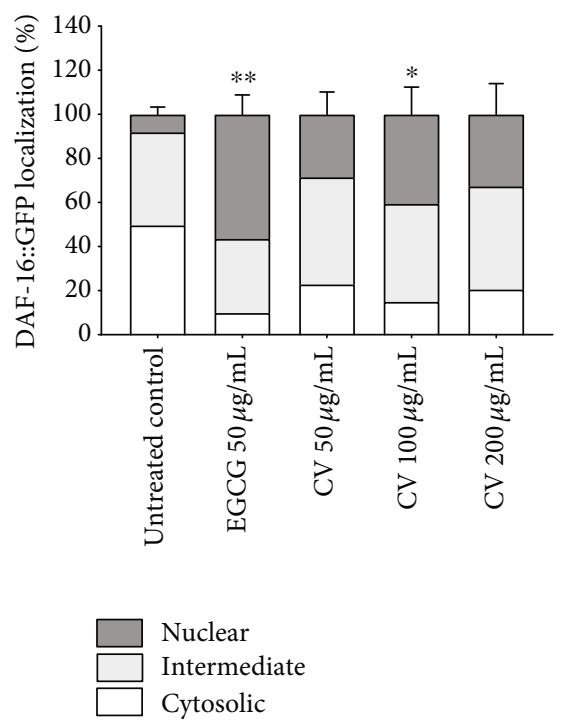

(c)

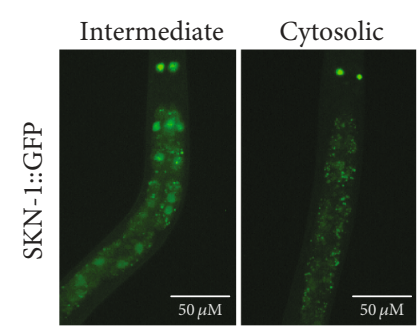

(b)

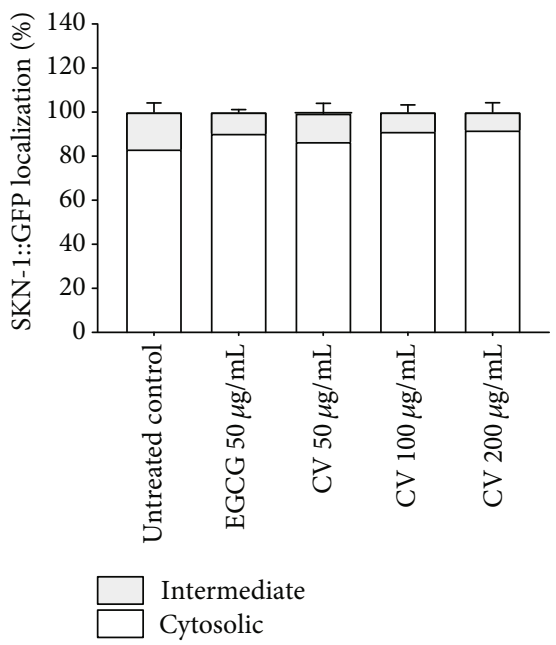

(d)

FIGURE 4: Effect of Caryocar villosum fruit shells (CV) on the intracellular localization of DAF-16 and SKN-1. (a) Representative images of TJ356 worms with nuclear, intermediate, and cytosolic DAF-16::GFP localization. (b) Representative images of LD1 worms with intermediate and cytosolic SKN-1::GFP localization. (c) Intracellular localization of DAF-16. (d) Intracellular localization of SKN-1. The results are presented as mean percentage of worms showing each pattern of localization of at least three independent experiments. For DAF-16::GFP, error bars show the mean percentage of worms exhibiting nuclear localization \pm SEM, and the statistical differences also refer to this pattern of localization $(* p<0.05, * * p<0.01$, compared to the untreated control). For SKN-1::GFP, error bars show the mean percentage of worms exhibiting intermediate localization \pm SEM.

$3.37 \%$, in comparison to the juglone control $(p<0.0001)$. Representative fluorescence images of the living worms analyzed for the quantification of $g s t-4$ and $h s p-16.2$ can be found in the supplementary information (Figures S4 and S5).

Juglone also increased the expression of gst-4 and hsp16.2 in wild-type worms at the transcriptional level. The expression of gst-4 and hsp-16.2 increased 8.5-fold and 9.3fold, respectively, in comparison to the untreated control (Figure 6(b)). For both genes, the GFP intensity was consistent with the relative mRNA expression levels (Figures 6(e) and $6(\mathrm{f}))$. In worms subjected to the same dose of juglone and $200 \mu \mathrm{g} / \mathrm{mL} \mathrm{CV}$, gst-4 and $h s p-16.2$ expression decreased to 0.33 and 0.17 -fold, respectively, in comparison to the juglone treatment $(p<0.0001)$.

GST-4 is a phase II detoxification enzyme that catalyzes the conjugation of several exogenous and endogenous hydrophobic electrophiles with the reduced form of glutathione, resulting in the detoxification of ROS and xenobiotic compounds [76]. HSP-16.2 acts as a molecular chaperone, binding to partially denatured proteins to avoid protein aggregation. The capacity of dietary antioxidants to suppress the stress- induced expression of genes coding for these proteins is widely interpreted as proof of their ability to reduce oxidative stress in C. elegans [38, 77-79]. Accordingly, the downregulation of gst4 and $h s p-16.2$ elicited by CV further confirms the extract's ability to protect $C$. elegans from oxidative stress and, presumably, from the damage it may induce.

3.3.3. Lifespan Extension. Several studies on plant extracts containing polyphenols and/or saponins report a correlation between stress resistance and lifespan extension [8085]. As CV improved the oxidative stress status of C. elegans, in another set of experiments, we tested its effects on the lifespan of wild-type worms. The extract significantly induced lifespan extension at all concentrations tested (Figure 7(a)) (Table 4). At $200 \mu \mathrm{g} / \mathrm{mL}$, maximum extension was observed, CV increased the median survival of wildtype worms from 23 to $27 \mathrm{~d}(17.29 \%)$, in comparison to the untreated control $(p<0.0001)$. Taking the previously mentioned studies into consideration, it is reasonable to assume that $\mathrm{CV}$ prolongs the lifespan of C. elegans as a result of its overall antioxidant activity. 


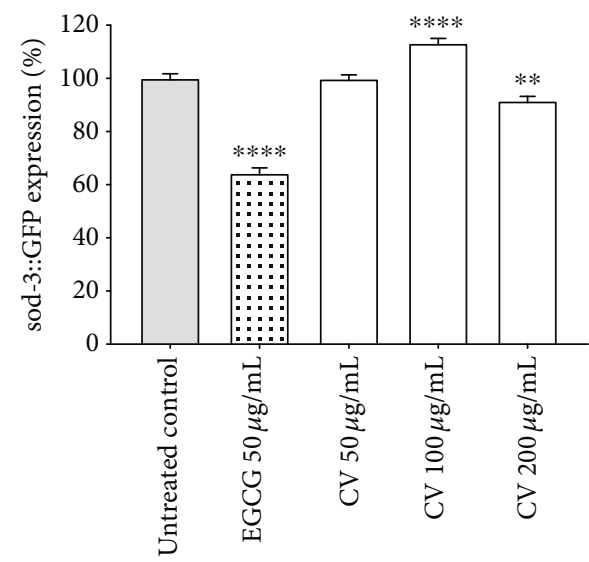

(a)

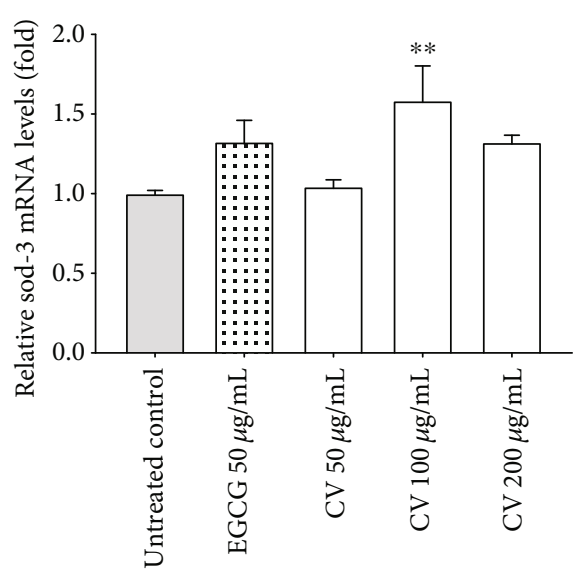

(c)

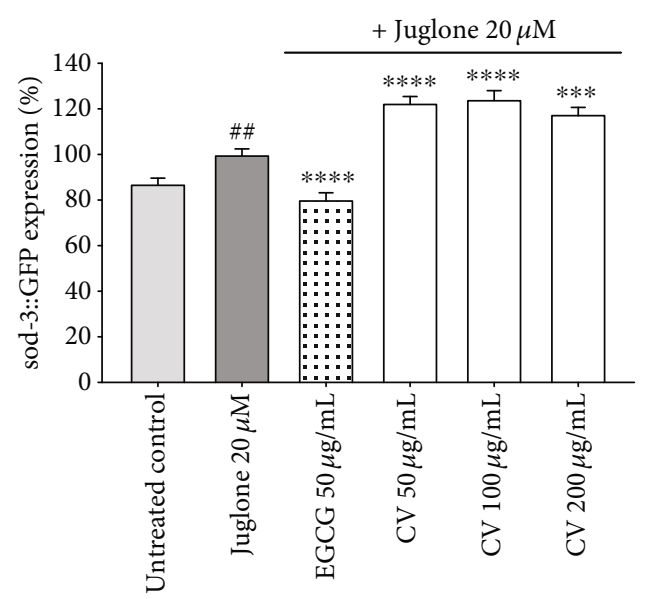

(b)

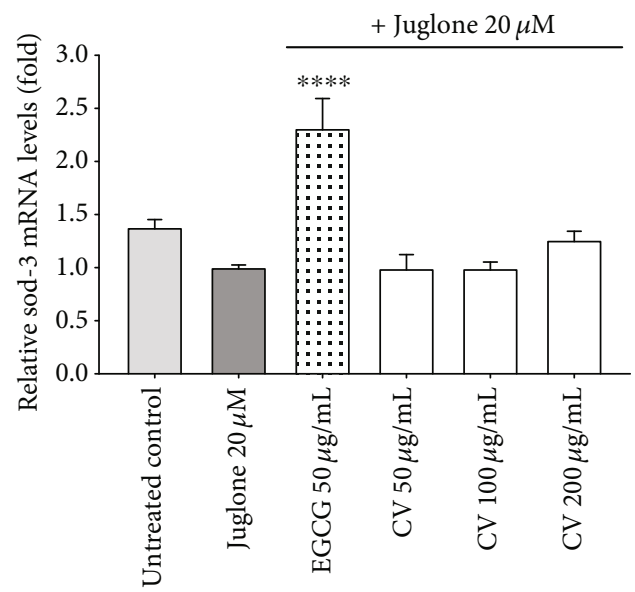

(d)

FIGURE 5: Effect of Caryocar villosum fruit shells (CV) on superoxide dismutase 3 (sod-3) expression under basal and mild oxidative stress, induced by a dose of $20 \mu \mathrm{M}$ juglone. (a) sod-3::GFP expression levels under basal stress conditions. (b) sod-3::GFP expression levels under juglone-induced oxidative stress. (c) Relative sod-3 mRNA levels of wild-type worms under basal stress conditions. (d) Relative sod-3 mRNA levels of wild-type worms under $20 \mu \mathrm{M}$ juglone-induced oxidative stress. Data are representative of three independent experiments. GFP expression levels are expressed as mean percentage of untreated control (basal stress) or juglone (induced stress) \pm SEM $\left(* * p<0.01, * * * p<0.001\right.$, and $* * * * p<0.0001$, compared to the respective control) $\left({ }^{\# \#} p<0.01\right.$, compared to the untreated control). Relative mRNA levels are presented as mean fold relative mRNA levels, calculated from $\Delta \Delta \mathrm{Ct}$ values normalized to $c d c-42$ as a reference gene $(* * p<0.01, * * * * p<0.0001$, compared to juglone).

To clarify the role of DAF-16 and SKN-1 in the CVmediated lifespan extension, we investigated the effect of $200 \mu \mathrm{g} / \mathrm{mL} \mathrm{CV}$ on the lifespan of mutant worms for both transcription factors. CV failed to extend the lifespan of both mutants (Figures 7(b) and 7(c)) (Table 4). Based on these results, it may be inferred that $\mathrm{CV}$ prolongs $C$. elegans lifespan in a DAF-16 and SKN-1 dependent manner.

Whereas the vast majority of studies confirm the connection between increased stress tolerance and prolonged lifespan, a growing body of evidence demonstrates that defense against oxidative stress per se does not fully explain the mechanisms by which antioxidants extend longevity [86]. In part, our study is in agreement with this evidence. Firstly, CV treatment did not extend the lifespan in daf-16 and $s k n-1$ mutants, but significantly improved their oxidative stress status reducing the levels of ROS and increasing the survival to a lethal dose of juglone. Moreover, enhanced stress resistance and lifespan extension most likely occurred by different mechanisms of action. Stress resistance was apparently not strictly dependent on DAF-16 and SKN-1, although it involved the activation of DAF-16 and the upregulation of its direct target, sod-3. On the contrary, CV-mediated lifespan extension required DAF-16 and SKN-1, confirming the involvement of IIS signaling in the observed effects.

\subsubsection{Feeding Behavior, Development, and Reproduction.} Dietary restriction is one of the best characterized interventions to extend lifespan and stress resistance in C. elegans [87]. CV treatment at the highest concentration tested did not affect bacterial growth neither influenced the feeding behavior of worms, assessed by means of bacterial clearance. The worms treated with $200 \mu \mathrm{g} / \mathrm{mL}$ CV showed a similar food intake pattern of that observed among untreated worms (Figure $8(\mathrm{a})$ ). This result prompts us to rule out dietary 


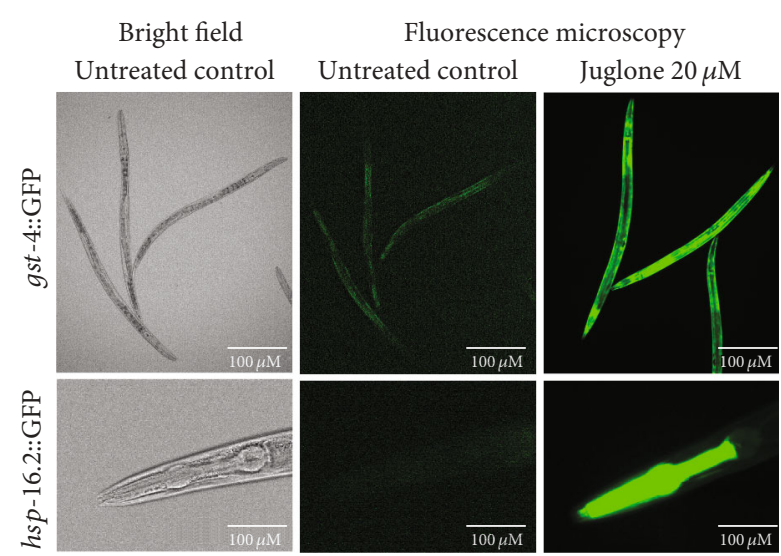

(a)

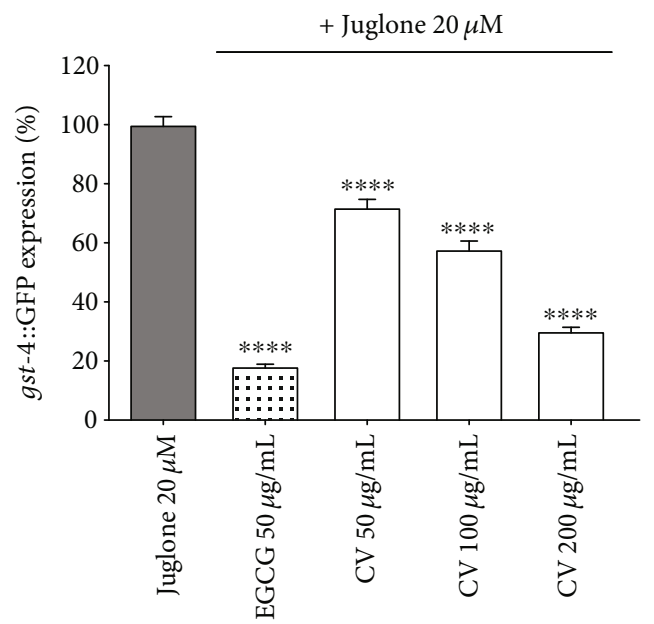

(c)

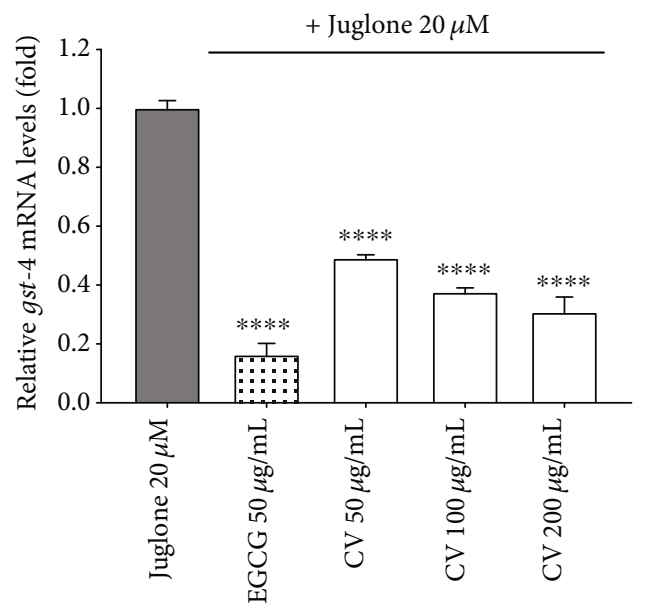

(e)

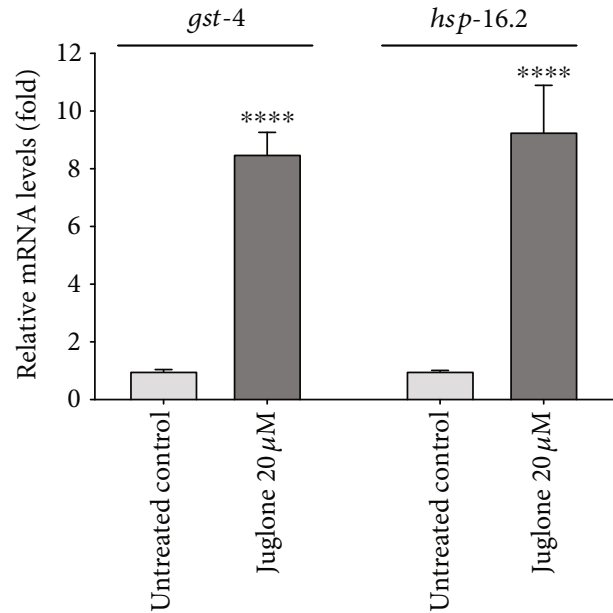

(b)

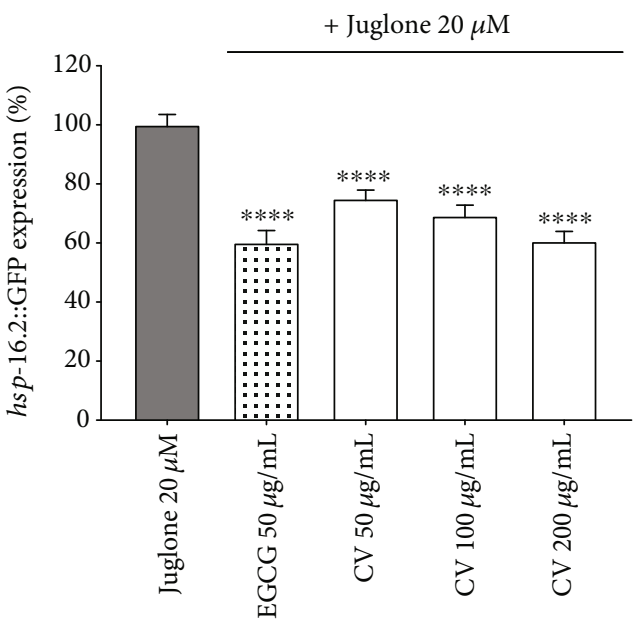

(d)

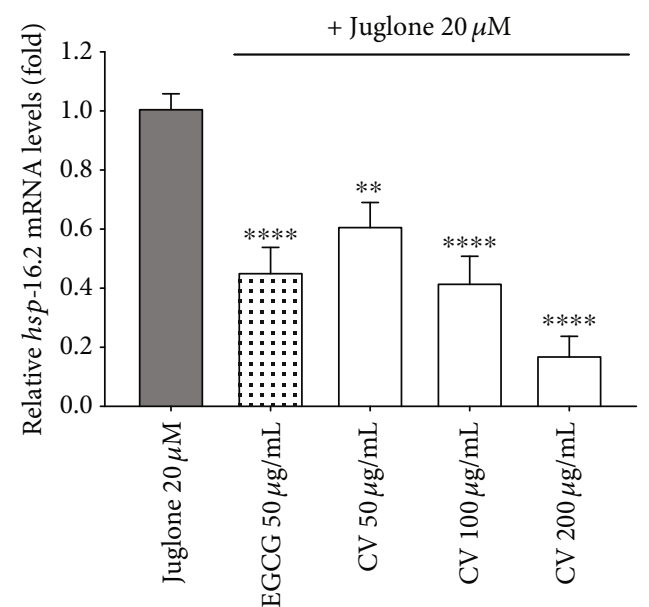

(f)

Figure 6: Effect of Caryocar villosum fruit shells (CV) on heat-shock protein 16.2 (hsp-16.2) and glutathione $S$-transferase 4 (gst-4) expression under mild oxidative stress, induced by a dose of $20 \mu \mathrm{M}$ juglone. (a) Representative images of CL2166 (gst-4::GFP) and TJ375 (hsp-16.2::GFP) worms. (b) Relative mRNA levels of gst-4 and $h s p-16.2$ of untreated and juglone treated wild-type worms. (c) gst-4::GFP expression levels. (d) $h s p-16.2::$ GFP expression levels. (e) Relative gst-4 mRNA levels of wild-type worms. (f) Relative hsp-16.2 mRNA levels of wild-type worms. Data are representative of three independent experiments. GFP expression levels are expressed as mean percentage of juglone \pm SEM $(* * * * p<0.001$, compared to juglone). Relative mRNA levels are presented as mean fold relative mRNA levels in comparison to the juglone treatment \pm SEM, normalized to $c d c-42$ as a reference gene $(* * p<0.01, * * * * p<0.001$, compared to juglone). 


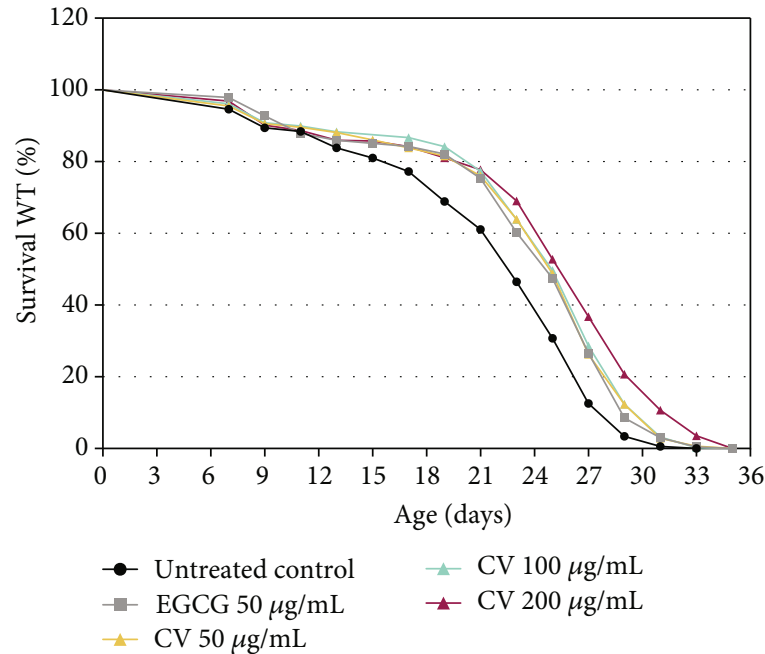

(a)

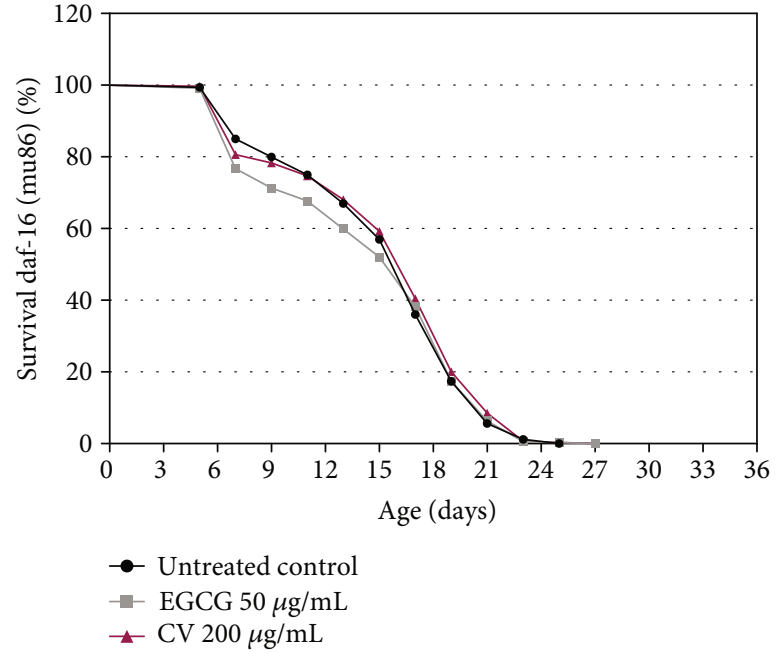

(b)

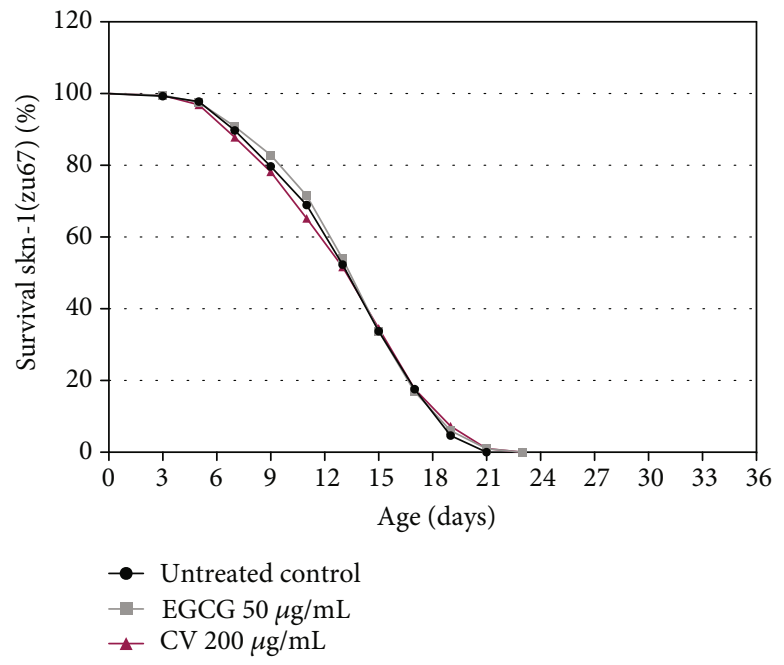

(c)

Figure 7: Lifespan of wild-type (a) and mutant worms for daf-16 (b) and skn-1 (c) treated with Caryocar villosum fruit shells (CV). Lifespan is expressed as mean percentage of survival of at least three independent experiments.

TABle 4: Mean and median lifespan of wild-type (N2) and mutant worms for daf-16 (CF1038) and skn-1 (EU1) treated with Caryocar villosum fruit shells $(\mathrm{CV})$.

\begin{tabular}{|c|c|c|c|c|c|}
\hline Strain & Treatment $(\mu \mathrm{g} / \mathrm{mL})$ & Mean lifespan \pm SE (days) & Median lifespan \pm SE (days) & $N$ & $p$ value $^{\mathrm{a}}$ \\
\hline \multirow{5}{*}{$\mathrm{N} 2$} & Untreated control & $21.77 \pm 0.29$ & $23.00 \pm 0.29$ & 501 & - \\
\hline & EGCG 50 & $23.75 \pm 0.30$ & $25.00 \pm 0.27$ & 470 & $<0.0001$ \\
\hline & CV 50 & $23.92 \pm 0.30$ & $25.00 \pm 0.24$ & 488 & $<0.0001$ \\
\hline & CV 100 & $24.17 \pm 0.30$ & $25.00 \pm 0.27$ & 437 & $<0.0001$ \\
\hline & CV 200 & $24.68 \pm 0.34$ & $27.00 \pm 0.28$ & 449 & $<0.0001$ \\
\hline \multirow{3}{*}{ CF1038 } & Untreated control & $15.46 \pm 0.27$ & $17.00 \pm 0.25$ & 339 & - \\
\hline & EGCG 50 & $14.75 \pm 0.30$ & $17.00 \pm 0.49$ & 334 & 0.63 \\
\hline & CV 200 & $15.61 \pm 0.30$ & $17.00 \pm 0.30$ & 304 & 0.27 \\
\hline \multirow{3}{*}{ EU1 } & Untreated control & $13.88 \pm 0.20$ & $15.00 \pm 0.27$ & 409 & - \\
\hline & EGCG 50 & $14.08 \pm 0.19$ & $15.00 \pm 0.25$ & 415 & 0.54 \\
\hline & CV 200 & $13.93 \pm 0.12$ & $15.00 \pm 0.33$ & 385 & 0.69 \\
\hline
\end{tabular}

${ }^{a} p$ values (treatment vs. untreated control) were determined by the log-rank test. 


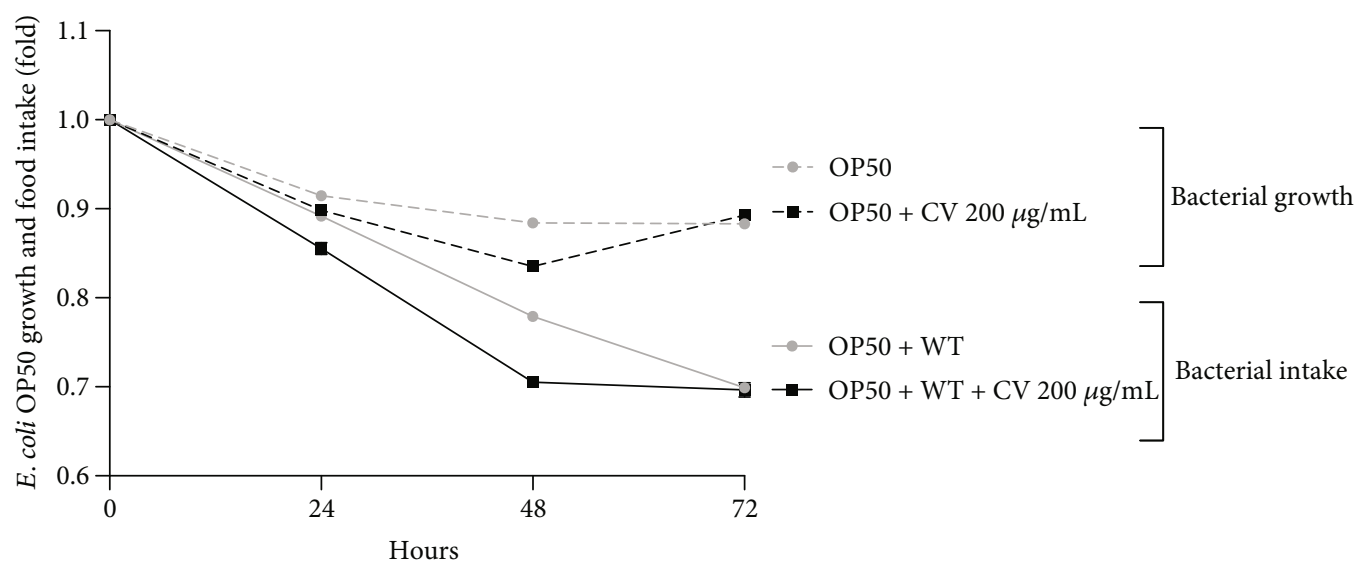

(a)

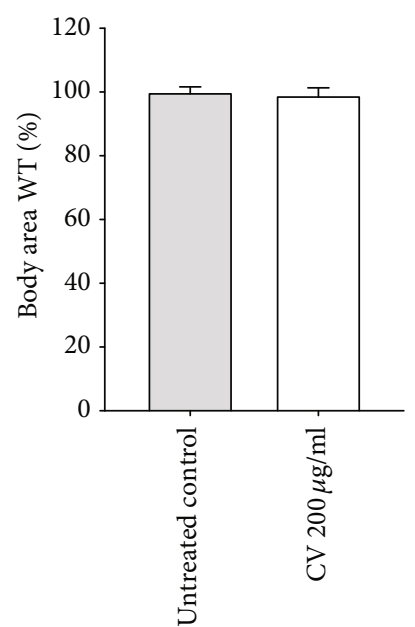

(b)

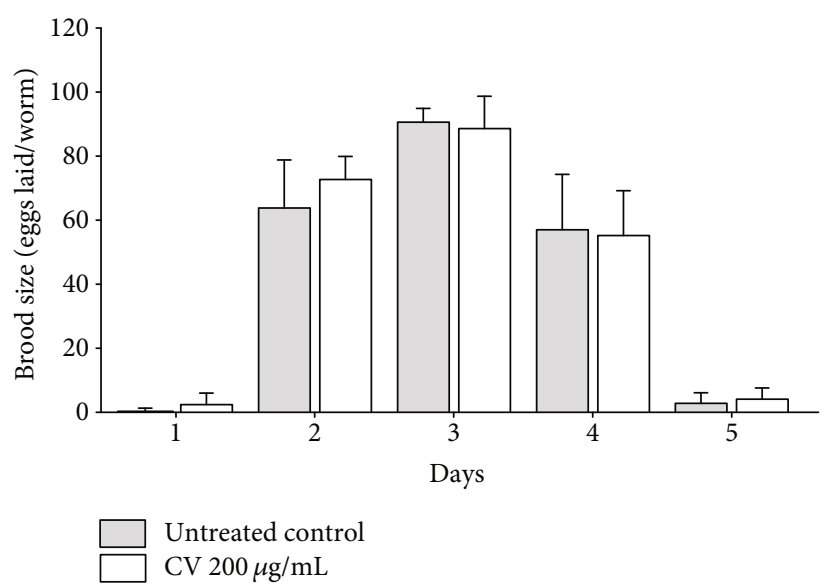

(c)

Figure 8: Impact of Caryocar villosum fruit shells (CV) on the feeding behavior, development, and reproduction of wild-type worms. (a) E. coli OP50 growth and food intake by means of bacterial clearance. (b) Body area of wild-type worms on the first day of adulthood. (c) Brood size. Data are representative of three independent experiments. Bacterial growth and intake are presented as fold calculated from the absorbance at day 0 . Body area is expressed as percentage compared to the untreated control (mean \pm SEM). Brood size represents the number of eggs laid per worm during the reproductive period (mean $\pm \mathrm{SEM}$ ).

restriction as the mechanism through which $\mathrm{CV}$ enhances stress resistance and prolongs lifespan in C. elegans.

According to the disposable soma theory, throughout the aging process, the organisms distribute their metabolic resources among various physiological processes in an effort to grow, survive, and reproduce [88]. If higher energy is put into lifespan extension (survival), energetic resources will allocate mainly into maintenance of cellular homeostasis (e.g., antioxidant defense, repair systems of nucleic acids, and proteins) resulting in compromised body growth and reproduction. $\mathrm{CV}$ extract is rich in polyphenols which were previously shown to extend $C$. elegans lifespan in line with the disposable soma theory [89]. To evaluate whether CV treatment affects growth and/or reproduction, we measured its effect on the worm's body area and brood size. CV at $200 \mu \mathrm{g} / \mathrm{mL}$ did not affect the body size of wild-type worms nor the daily number of eggs laid per worm, in comparison to untreated worms (Figures 8(b) and 8(c)). Altogether, these results apparently exclude disposable soma as an explanation for the ability of CV to promote longevity in C. elegans.
EGCG, a polyphenol with a gallic acid moiety in its structure, has been consistently found to improve stress resistance and to prolong lifespan in C. elegans $[62,90-92]$. Due to this background, it was employed as a positive control in this study. EGCG and CV revealed similar results; both reduced the intracellular levels of ROS rescued the worms from a lethal dose of juglone, activated DAF-16, down-regulated stress-responsive genes ( $h s p-16.2$ and $g s t-4)$, and extended lifespan in a DAF-16- and SKN-1-dependent manner.

To the best of our knowledge, from the polyphenols tentatively identified in $\mathrm{CV}$, only gallic acid and ellagic acid were previously investigated in $C$. elegans, with regard to their putative antioxidant and lifespan-promoting effects. In a study comparing the mechanisms by which several polyphenols extend lifespan, Saul et al. [89] demonstrated that gallic acid $(100-300 \mu \mathrm{M})$ and ellagic acid $(50 \mu \mathrm{M})$ were able to significantly extend the lifespan of wild-type worms fed with living bacteria (as performed in the present study) but failed to increase survival under oxidative stress. At higher concentrations, gallic acid was devoid of toxicity, while ellagic acid 
exhibited toxic effects, reducing the lifespan of the worms under basal and oxidative stress conditions. According to the authors, the lifespan-promoting activity of gallic and ellagic acid does not seem to be correlated with their antioxidant properties. Apparently, ellagic acid might not only act through a hormetic mechanism but also as a caloric restriction mimetic, as it affects $C$. elegans feeding behavior through a chemorepellent activity. This effect was not observed for CV extract. Similarly to our results, the worm's growth and reproduction were not significantly affected, showing that gallic and ellagic acid, unlike other polyphenols, do not act in line with the disposable soma theory.

In two other studies, ellagic acid, at the same concentration previously tested, failed to extend the lifespan of wildtype worms [93, 94]. Ryu et al. [93] additionally showed the capacity of urolithin A, a digestive metabolite of ellagic acid, to sharply extend the lifespan of C. elegans (up to $45.4 \%$ ) and to regulate mitochondrial function by mitophagy. These observations suggest that future studies on the digestive metabolites of hydrolysable tannins, rather than on their metabolic precursors, could provide important insights into the antioxidant and antiaging potential of tannin-rich plant extracts for human health.

Regarding the saponin content, none of the triterpenoid saponins identified in CV have yet been investigated. However, an isolated triterpenoid saponin from Panax ginseng [95], a steroidal saponin from Asparagus racemosus [96], and plant extracts particularly rich in triterpenoid saponins $[97,98]$ were previously reported to enhance stress resistance and to prolong lifespan in C. elegans. In the study of Magid et al. [50], saponins accounted for only $0.5 \%$ of the total composition of a methanol extract of piquiá shells. Since saponins are able to facilitate the transport of polar compounds across the cell membrane, if not bioactive, they may possibly contribute to enhance the bioavailability of the bioactive compounds of CV [99].

More studies are certainly needed to clarify which compounds, or combination of compounds, are responsible for the antioxidant and antiaging activities exerted by $\mathrm{CV}$ in $\mathrm{C}$. elegans. Nonetheless, we hypothesize that the presence of free gallic and ellagic acids might be determinant for the bioactivities herein reported. These phenolic acids possess a low molecular weight, being thus presumably more bioavailable than hydrolysable tannins, which encompass highly polymerized compounds that have to be cleaved into phenolic acids in the intestinal tract in order to be absorbed.

\section{Conclusions}

Taken together, our results demonstrate the potential of piquiá shells dietary supplementation to promote stress resistance and lifespan extension in C. elegans. These effects implicated distinct mechanisms of action. Improved oxidative status and increased resistance to juglone-induced oxidative stress did not strictly require DAF-16 and SKN-1, while piquiá-mediated lifespan extension was shown to be dependent on both transcription factors.

In a scenario of increasing demand for antiaging interventions, our study highlights the underestimated potential of fruit waste as a source of bioactive compounds, which may be of interest for the production of antiaging dietary supplements or other applications at an industrial scale. In the specific case of piquiá shells, further studies using vertebrate model organisms are required to demonstrate whether its shells qualify as nutraceuticals. Such studies should address the bioavailability of the extract after digestion and its safety profile, taking into particular consideration the potential toxicity of gallotannins and the dual role of saponins as antinutrients or as absorption enhancers.

\section{Data Availability}

All data used to support the findings of this study are available from the corresponding author upon request.

\section{Conflicts of Interest}

The authors declare that there are no conflicts of interest regarding the publication of this paper.

\section{Authors' Contributions}

M.R., H.P., and M.W. conceived and designed the study. M.R. and H.P. performed experiments and analyzed data. P.W. performed LC-MS/MS analysis and analyzed data. E.L. collected the plant material and performed the extraction. M.R. wrote the original draft. M.W. supervised the study, administrated the project, and acquired the funding. All authors read, reviewed, and edited the manuscript and approved the submitted version.

\section{Acknowledgments}

M.R. was financially supported by CusanuswerkStudienförderung. Caenorhabditis elegans strains were provided by the CGC, which is funded by the NIH Office of Research Infrastructure Programs (P40 OD010440). We acknowledge the financial support by Deutsche Forschungsgemeinschaft within the funding program Open Access Publishing, by the Baden-Württemberg Ministry of Science, Research, and the Arts, and by Ruprecht-Karls-Universität, Heidelberg.

\section{Supplementary Materials}

Figure S1: representative fluorescence images of N2, CF1038, EU1, and VC475 worms analyzed for the quantification of ROS accumulation. Figure S2: representative fluorescence images of CF1553 worms analyzed for the quantification of sod-3::GFP levels under basal stress conditions. Figure S3: representative fluorescence images of CF1553 worms analyzed for the quantification of sod-3::GFP levels under juglone-induced oxidative stress. Figure S4: representative fluorescence images of CL2166 worms analyzed for the quantification of gst-4::GFP levels under juglone-induced oxidative stress. Figure S5: representative fluorescence images of TJ375 worms analyzed for the quantification of hsp-16::GFP levels under juglone-induced oxidative stress. (Supplementary Materials) 


\section{References}

[1] A. Y. Chang, V. F. Skirbekk, S. Tyrovolas, N. J. Kassebaum, and J. L. Dieleman, "Measuring population ageing: an analysis of the Global Burden of Disease Study 2017," The Lancet Public Health, vol. 4, no. 3, pp. e159-e167, 2019.

[2] F. A. Kluge, J. R. Goldstein, and T. C. Vogt, "Transfers in an aging European Union," The Journal of the Economics of Ageing, vol. 13, pp. 45-54, 2019.

[3] K. Kumar, A. N. Yadav, V. Kumar, P. Vyas, and H. S. Dhaliwal, "Food waste: a potential bioresource for extraction of nutraceuticals and bioactive compounds," Bioresources and Bioprocessing, vol. 4, no. 1, p. 18, 2017.

[4] H. Kowalska, K. Czajkowska, J. Cichowska, and A. Lenart, "What's new in biopotential of fruit and vegetable byproducts applied in the food processing industry," Trends in Food Science \& Technology, vol. 67, pp. 150-159, 2017.

[5] J. F. Ayala-Zavala, V. Vega-Vega, C. Rosas-Domínguez et al., "Agro-industrial potential of exotic fruit byproducts as a source of food additives," Food Research International, vol. 44, no. 7, pp. 1866-1874, 2011.

[6] M. F. Fraga, "Genetic and epigenetic regulation of aging," Current Opinion in Immunology, vol. 21, no. 4, pp. 446453, 2009.

[7] A. Höhn, D. Weber, T. Jung et al., "Happily (n)ever after: aging in the context of oxidative stress, proteostasis loss and cellular senescence," Redox Biology, vol. 11, pp. 482-501, 2017.

[8] T. Finkel and N. J. Holbrook, "Oxidants, oxidative stress and the biology of ageing," Nature, vol. 408, no. 6809, pp. 239$247,2000$.

[9] M. S. Cooke, M. D. Evans, M. Dizdaroglu, and J. Lunec, "Oxidative DNA damage: mechanisms, mutation, and disease," The FASEB Journal, vol. 17, no. 10, pp. 1195-1214, 2003.

[10] H. Sies, C. Berndt, and D. P. Jones, "Oxidative stress," Annual Review of Biochemistry, vol. 86, no. 1, pp. 715-748, 2017.

[11] L. G. del Valle, "Oxidative stress in aging: theoretical outcomes and clinical evidences in humans," Biomedicine \& Aging Pathology, vol. 1, no. 1, pp. 1-7, 2011.

[12] K. S. Bhullar and H. P. V. Rupasinghe, "Polyphenols: multipotent therapeutic agents in neurodegenerative diseases," Oxidative Medicine and Cellular Longevity, vol. 2013, Article ID 891748, 18 pages, 2013.

[13] M. Cesari, M. Pahor, B. Bartali et al., "Antioxidants and physical performance in elderly persons: the Invecchiare in Chianti (InCHIANTI) study," The American Journal of Clinical Nutrition, vol. 79, no. 2, pp. 289-294, 2004.

[14] G. Davi, F. Santilli, and C. Patrono, "Nutraceuticals in diabetes and metabolic syndrome," Cardiovascular Therapeutics, vol. 28 , no. 4 , p. $226,2010$.

[15] R. Kotecha, A. Takami, and J. L. Espinoza, "Dietary phytochemicals and cancer chemoprevention: a review of the clinical evidence," Oncotarget, vol. 7, no. 32, pp. 5251752529, 2016.

[16] S. Wang, J. P. Melnyk, R. Tsao, and M. F. Marcone, "How natural dietary antioxidants in fruits, vegetables and legumes promote vascular health," Food Research International, vol. 44, no. 1, pp. 14-22, 2011.

[17] A.-J. Ding, S.-Q. Zheng, X.-B. Huang et al., "Current perspective in the discovery of anti-aging agents from natural products," Natural Products and Bioprospecting, vol. 7, no. 5, pp. 335-404, 2017.
[18] C. Gupta and D. Prakash, "Nutraceuticals for geriatrics," Journal of Traditional and Complementary Medicine, vol. 5, no. 1, pp. 5-14, 2015.

[19] C. Kenyon, "The plasticity of aging: insights from long-lived mutants," Cell, vol. 120, no. 4, pp. 449-460, 2005.

[20] T. Kaletta and M. O. Hengartner, "Finding function in novel targets: C. elegans as a model organism," Nature Reviews Drug Discovery, vol. 5, no. 5, pp. 387-399, 2006.

[21] D. Barardo, D. Thornton, H. Thoppil et al., "The DrugAge database of aging-related drugs," Aging Cell, vol. 16, no. 3, pp. 594-597, 2017.

[22] A. K. Corsi, B. Wightman, and M. Chalfie, "A transparent window into biology: a primer on Caenorhabditis elegans," Genetics, vol. 200, no. 2, pp. 387-407, 2015.

[23] M. Markaki and N. Tavernarakis, "Modeling human diseases in Caenorhabditis elegans," Biotechnology Journal, vol. 5, no. 12, pp. 1261-1276, 2010.

[24] G. T. Prance and M. Silva, "Monograph of Caryocaraceae," Flora Neotropica, vol. 12, pp. 1-75, 1973.

[25] R. P. Alves, C. Levis, and C. R. Clement, "Use and management of piquiá suggest in situ domestication along the Lower Tapajós River, Brazilian Amazonia," Economic Botany, vol. 70, no. 2, pp. 198-202, 2016.

[26] P. Grenand, C. Moretti, H. Jacquemin, and M. Prévost, "B-C (Basellaceae à Cyperaceae)," in Pharmacopées traditionnelles en Guyane: Créoles, Wayãpi, Palikur, IRD Éditions, 2004.

[27] W. Harand, R. S. Pinho, and L. P. Felix, "Alternative oilseeds for Northeastern Brazil: unrevealed potential of Brazilian biodiversity," Brazilian Journal of Botany, vol. 39, no. 1, pp. 169183, 2016.

[28] P. Shanley, Fruit Trees and Useful Plants in Amazonian Life, Food and Agriculture Organization of the United Nations (FAO), 2011.

[29] R. C. Chisté, M. Freitas, A. Z. Mercadante, and E. Fernandes, "The potential of extracts of Caryocar villosum pulp to scavenge reactive oxygen and nitrogen species," Food Chemistry, vol. 135, no. 3, pp. 1740-1749, 2012.

[30] G. P. M. Barreto, M. T. Benassi, and A. Z. Mercadante, "Bioactive compounds from several tropical fruits and correlation by multivariate analysis to free radical scavenger activity," Journal of the Brazilian Chemical Society, vol. 20, no. 10, pp. 18561861, 2009.

[31] M. R. Almeida, J. D.’ A. C. Darin, L. C. Hernandes et al., “Antigenotoxic effects of piquiá (Caryocar villosum) in multiple rat organs," Plant Foods for Human Nutrition, vol. 67, no. 2, pp. 171-177, 2012.

[32] W. K. S. Xavier, B. J. Medeiros, C. S. Lima et al., "Topical antiinflammatory action of Caryocar villosum oil (Aubl) Pers," Journal of Applied Pharmaceutical Science, vol. 1, p. 62, 2011.

[33] K. K. de Lima Yamaguchi, C. V. Lamarão, E. Aranha et al., "HPLC-DAD profile of phenolic compounds, cytotoxicity, antioxidant and anti-inflammatory activities of the amazon fruit Caryocar villosum," Química Nova, vol. 40, no. 5, pp. 483-490, 2017.

[34] H. Peixoto, M. Roxo, H. Koolen et al., "Calycophyllum spruceanum (Benth.), the amazonian "Tree of youth" prolongs longevity and enhances stress resistance in Caenorhabditis elegans," Molecules, vol. 23, no. 3, p. 534, 2018.

[35] T. Stiernagle, "Maintenance of C. elegans," WormBook, 2006.

[36] K. Strange, M. Christensen, and R. Morrison, "Primary culture of Caenorhabditis elegans developing embryo cells for 
electrophysiological, cell biological and molecular studies," Nature Protocols, vol. 2, no. 4, pp. 1003-1012, 2007.

[37] H. Peixoto, M. Roxo, S. Krstin, T. Röhrig, E. Richling, and M. Wink, "An anthocyanin-rich extract of acai (Euterpe precatoria Mart.) increases stress resistance and retards agingrelated markers in Caenorhabditis elegans," Journal of Agricultural and Food Chemistry, vol. 64, no. 6, pp. 1283-1290, 2016.

[38] S. Abbas and M. Wink, "Green tea extract induces the resistance of Caenorhabditis elegans against oxidative stress," Antioxidants, vol. 3, no. 1, pp. 129-143, 2014.

[39] P. Link and M. Wink, "Isoliquiritigenin exerts antioxidant activity in Caenorhabditis elegans via insulin-like signaling pathway and SKN-1," Phytomedicine, vol. 55, pp. 119-124, 2019.

[40] L. Gayoso, M. Roxo, R. Y. Cavero et al., "Bioaccessibility and biological activity of Melissa officinalis, Lavandula latifolia and Origanum vulgare extracts: influence of an in vitro gastrointestinal digestion," Journal of Functional Foods, vol. 44, pp. 146-154, 2018.

[41] H. Li, M. Roxo, X. Cheng, S. Zhang, H. Cheng, and M. Wink, "Pro-oxidant and lifespan extension effects of caffeine and related methylxanthines in Caenorhabditis elegans," Food Chemistry: X, vol. 1, article 100005, 2019.

[42] R. L. Gomez-Amaro, E. R. Valentine, M. Carretero et al., "Measuring food intake and nutrient absorption in Caenorhabditis elegans," Genetics, vol. 200, no. 2, pp. 443-454, 2015.

[43] R. C. Chisté and A. Z. Mercadante, "Identification and quantification, by HPLC-DAD-MS/MS, of carotenoids and phenolic compounds from the Amazonian fruit Caryocar villosum," Journal of Agricultural and Food Chemistry, vol. 60, no. 23, pp. 5884-5892, 2011.

[44] M. Sobeh, M. F. Mahmoud, R. A. Hasan et al., "Chemical composition, antioxidant and hepatoprotective activities of methanol extracts from leaves ofTerminalia belliricaandTerminalia sericea(Combretaceae)," PeerJ, vol. 7, article e6322, 2019.

[45] C. C. Wyrepkowski, D. L. M. Gomes da Costa, A. P. Sinhorin et al., "Characterization and quantification of the compounds of the ethanolic extract from Caesalpinia ferrea stem bark and evaluation of their mutagenic activity," Molecules, vol. 19, no. 10, pp. 16039-16057, 2014.

[46] N. M. Hegazi, M. Sobeh, S. Rezq et al., "Characterization of phenolic compounds from Eugenia supra-axillaris leaf extract using HPLC-PDA-MS/MS and its antioxidant, anti-inflammatory, antipyretic and pain killing activities in vivo," Scientific Reports, vol. 9, no. 1, article 11122, 2019.

[47] Z. Yisimayili, R. Abdulla, Q. Tian et al., "A comprehensive study of pomegranate flowers polyphenols and metabolites in rat biological samples by high-performance liquid chromatography quadrupole time-of-flight mass spectrometry," Journal of Chromatography A, vol. 1604, article 460472, 2019.

[48] M. D. Catarino, A. M. S. Silva, M. T. Cruz, and S. M. Cardoso, "Antioxidant and anti-inflammatory activities of Geranium robertianum L. decoctions," Food \& Function, vol. 8, no. 9, pp. 3355-3365, 2017.

[49] A. Taamalli, I. Iswaldi, D. Arráez-Román, A. Segura-Carretero, A. Fernández-Gutiérrez, and M. Zarrouk, "UPLC-QTOF/MS for a rapid characterisation of phenolic compounds from leaves of Myrtus communis L," Phytochemical Analysis, vol. 25, no. 1, pp. 89-96, 2014.

[50] A. A. Magid, L. Voutquenne, D. Harakat et al., "Triterpenoid Saponins from the fruits of Caryocar villosum," Journal of Natural Products, vol. 69, no. 6, pp. 919-926, 2006.
[51] A. A. Magid, L. Voutquenne-Nazabadioko, I. Renimel, D. Harakat, C. Moretti, and C. Lavaud, "Triterpenoid saponins from the stem bark of Caryocar villosum," Phytochemistry, vol. 67, no. 19, pp. 2096-2102, 2006.

[52] A. A. Magid, L. Voutquenne, C. Moretti, C. Long, and C. Lavaud, "Triterpenoid saponins from the fruits of Caryocar glabrum," Journal of Natural Products, vol. 69, no. 2, pp. 196205, 2006.

[53] C. A. Breda, A. M. Gasperini, V. L. Garcia et al., "Phytochemical analysis and antifungal activity of extracts from leaves and fruit residues of Brazilian savanna plants aiming its use as safe fungicides," Natural Products and Bioprospecting, vol. 6, no. 4, pp. 195-204, 2016.

[54] A. A. Magid, L. Voutquenne-Nazabadioko, D. Harakat, C. Moretti, and C. Lavaud, "Phenolic glycosides from the stem bark of Caryocar villosum and C. glabrum," Journal of Natural Products, vol. 71, no. 5, pp. 914-917, 2008.

[55] C. J. Kenyon, "The genetics of ageing," Nature, vol. 464, no. 7288, pp. 504-512, 2010.

[56] J. M. A. Tullet, M. Hertweck, J. H. An et al., "Direct Inhibition of the Longevity-Promoting Factor SKN-1 by Insulin-like Signaling in C. elegans," Cell, vol. 132, no. 6, pp. 1025-1038, 2008.

[57] J. N. Landis and C. T. Murphy, "Integration of diverse inputs in the regulation of Caenorhabditis elegans DAF-16/FOXO," Developmental Dynamics, vol. 239, no. 5, pp. 1405-1412, 2010.

[58] S. S. Lee, S. Kennedy, A. C. Tolonen, and G. Ruvkun, "DAF-16 target genes that control C. elegans life-span and metabolism," Science, vol. 300, no. 5619, pp. 644-647, 2003.

[59] C. F. Labuschagne and A. B. Brenkman, "Current methods in quantifying ROS and oxidative damage in Caenorhabditis elegans and other model organism of aging," Ageing Research Reviews, vol. 12, no. 4, pp. 918-930, 2013.

[60] M. M. Senchuk, D. J. Dues, and J. M. van Raamsdonk, "Measuring oxidative stress in Caenorhabditis elegans: paraquat and juglone sensitivity assays," Bio-Protocol, vol. 7, no. 1, 2017.

[61] E. de Castro, S. Hegi de Castro, and T. E. Johnson, "Isolation of long-lived mutants in Caenorhabditis elegans using selection for resistance to juglone," Free Radical Biology and Medicine, vol. 37, no. 2, pp. 139-145, 2004.

[62] S. Abbas and M. Wink, "Epigallocatechin gallate from green tea (Camellia sinensis) increases lifespan and stress resistance in Caenorhabditis elegans," Planta Medica, vol. 75, no. 3, pp. 216-221, 2009.

[63] V. Calabrese, C. Cornelius, A. Trovato-Salinaro et al., "The hormetic role of dietary antioxidants in free radical-related diseases," Current Pharmaceutical Design, vol. 16, no. 7, pp. $877-883,2010$.

[64] S. I. S. Rattan, "Hormesis in aging," Ageing Research Reviews, vol. 7, no. 1, pp. 63-78, 2008.

[65] S. Govindan, M. Amirthalingam, K. Duraisamy, T. Govindhan, N. Sundararaj, and S. Palanisamy, "Phytochemicals-induced hormesis protects Caenorhabditis elegans against $\alpha$-synuclein protein aggregation and stress through modulating HSF-1 and SKN-1/Nrf2 signaling pathways," Biomedicine \& Pharmacotherapy, vol. 102, pp. 812-822, 2018.

[66] E. F. Fang, T. B. Waltz, H. Kassahun et al., "Tomatidine enhances lifespan and healthspan in C. elegans through mitophagy induction via the SKN-1/Nrf2 pathway," Scientific Reports, vol. 7, no. 1, article 46208, 2017.

[67] K. Pietsch, N. Saul, S. Chakrabarti, S. R. Stürzenbaum, R. Menzel, and C. E. W. Steinberg, "Hormetins, antioxidants 
and prooxidants: defining quercetin-, caffeic acid- and rosmarinic acid-mediated life extension in C. elegans," Biogerontology, vol. 12, no. 4, pp. 329-347, 2011.

[68] C. Duangjan, P. Rangsinth, X. Gu, M. Wink, and T. Tencomnao, "Lifespan extending and oxidative stress resistance properties of a leaf extracts from Anacardium occidentale L. in Caenorhabditis elegans," Oxidative Medicine and Cellular Longevity, vol. 2019, Article ID 9012396, 16 pages, 2019.

[69] M. A. Wilson, B. Shukitt-Hale, W. Kalt, D. K. Ingram, J. A. Joseph, and C. A. Wolkow, "Blueberry polyphenols increase lifespan and thermotolerance in Caenorhabditis elegans," Aging Cell, vol. 5, no. 1, pp. 59-68, 2006.

[70] B. C. Azevedo, M. Roxo, M. C. Borges et al., "Antioxidant activity of an aqueous leaf extract from Uncaria tomentosa and its major alkaloids mitraphylline and isomitraphylline in Caenorhabditis elegans," Molecules, vol. 24, no. 18, article 3299, 2019.

[71] E. B. Lee, D. Ahn, B. J. Kim et al., "Genistein from Vigna angularis extends lifespan in Caenorhabditis elegans," Biomolecules \& Therapeutics, vol. 23, no. 1, pp. 77-83, 2015.

[72] K. Ye, C.-B. Ji, X.-W. Lu et al., "Resveratrol attenuates radiation damage in Caenorhabditis elegans by preventing oxidative stress," Journal of Radiation Research, vol. 51, no. 4, pp. 473479, 2010.

[73] A. Kampkötter, C. Timpel, R. F. Zurawski et al., "Increase of stress resistance and lifespan of Caenorhabditis elegans by quercetin," Comparative Biochemistry and Physiology Part B: Biochemistry and Molecular Biology, vol. 149, no. 2, pp. 314323, 2008.

[74] M. M. Senchuk, D. J. Dues, C. E. Schaar et al., "Activation of DAF-16/FOXO by reactive oxygen species contributes to longevity in long-lived mitochondrial mutants in Caenorhabditis elegans," PLoS Genetics, vol. 14, no. 3, article e1007268, 2018.

[75] C. T. Dolphin and I. A. Hope, "Caenorhabditis elegans reporter fusion genes generated by seamless modification of large genomic DNA clones," Nucleic Acids Research, vol. 34, no. 9, pp. e72-e72, 2006.

[76] B. Leiers, A. Kampkötter, C. G. Grevelding, C. D. Link, T. E. Johnson, and K. Henkle-Dührsen, "A stress-responsive glutathione S-transferase confers resistance to oxidative stress in Caenorhabditis elegans," Free Radical Biology and Medicine, vol. 34, no. 11, pp. 1405-1415, 2003.

[77] A. Kampkötter, T. Pielarski, R. Rohrig et al., "The Ginkgo biloba extract EGb761 reduces stress sensitivity, ROS accumulation and expression of catalase and glutathione S-transferase 4 in Caenorhabditis elegans," Pharmacological Research, vol. 55, no. 2, pp. 139-147, 2007.

[78] E. Wang and M. Wink, "Chlorophyll enhances oxidative stress tolerance in Caenorhabditis elegans and extends its lifespan," PeerJ, vol. 4, article e1879, 2016.

[79] W. Chen, L. Rezaizadehnajafi, and M. Wink, "Influence of resveratrol on oxidative stress resistance and life span in Caenorhabditis elegans," Journal of Pharmacy and Pharmacology, vol. 65, no. 5, pp. 682-688, 2013.

[80] H. Peixoto, M. Roxo, E. Silva et al., "Bark extract of the amazonian tree Endopleura uchi (Humiriaceae) extends lifespan and enhances stress resistance in Caenorhabditis elegans," Molecules, vol. 24, no. 5, p. 915, 2019.

[81] H. Peixoto, M. Roxo, T. Röhrig, E. Richling, X. Wang, and M. Wink, "Anti-aging and antioxidant potential of Paullinia cupana var. sorbilis: findings in Caenorhabditis elegans indi- cate a new utilization for roasted seeds of guarana," Medicine, vol. 4, no. 3, p. 61, 2017.

[82] Z. Wu, J. V. Smith, V. Paramasivam et al., "Ginkgo biloba extract EGb 761 increases stress resistance and extends life span of Caenorhabditis elegans," Cellular and Molecular Biology, vol. 48, no. 6, pp. 725-731, 2002.

[83] E. M. Vayndorf, S. S. Lee, and R. H. Liu, "Whole apple extracts increase lifespan, healthspan and resistance to stress in Caenorhabditis elegans," Journal of Functional Foods, vol. 5, no. 3, pp. 1235-1243, 2013.

[84] F. A. C. Wiegant, S. Surinova, E. Ytsma, M. Langelaar-Makkinje, G. Wikman, and J. A. Post, "Plant adaptogens increase lifespan and stress resistance in C. elegans," Biogerontology, vol. 10, no. 1, pp. 27-42, 2009.

[85] S.-Y. Jin, D.-Q. Li, S. Lu et al., "Ethanol extracts of Panax notoginseng increase lifespan and protect against oxidative stress in Caenorhabditis elegans via the insulin/IGF-1 signaling pathway," Journal of Functional Foods, vol. 58, pp. 218-226, 2019.

[86] D. J. Dues, E. K. Andrews, M. M. Senchuk, and J. M. Van Raamsdonk, "Resistance to stress can be experimentally dissociated from longevity," The Journals of Gerontology: Series A, vol. 74, no. 8, pp. 1206-1214, 2019.

[87] J. R. Cypser, D. Kitzenberg, and S.-K. Park, "Dietary restriction in C. elegans: recent advances," Experimental Gerontology, vol. 48, no. 10, pp. 1014-1017, 2013.

[88] T. B. Kirkwood, "The disposable soma theory," in The evolution of senescence in the tree of life, O. R. J. R. P. Shefferson and R. Salguero-Gómez, Eds., pp. 23-39, Cambridge University Press, Cambridge, United Kingdom, 2017.

[89] N. Saul, K. Pietsch, S. R. Stürzenbaum, R. Menzel, and C. E. W. Steinberg, "Diversity of polyphenol action in Caenorhabditis elegans: between toxicity and longevity," Journal of Natural Products, vol. 74, no. 8, pp. 1713-1720, 2011.

[90] A. Bartholome, A. Kampkötter, S. Tanner, H. Sies, and L.O. Klotz, "Epigallocatechin gallate-induced modulation of FoxO signaling in mammalian cells and C. elegans: FoxO stimulation is masked via PI3K/Akt activation by hydrogen peroxide formed in cell culture," Archives of Biochemistry and Biophysics, vol. 501, no. 1, pp. 58-64, 2010.

[91] M. K. Brown, J. L. Evans, and Y. Luo, "Beneficial effects of natural antioxidants EGCG and $\alpha$-lipoic acid on life span and agedependent behavioral declines in Caenorhabditis elegans," Pharmacology Biochemistry and Behavior, vol. 85, no. 3, pp. 620-628, 2006.

[92] L.-G. Xiong, Y.-J. Chen, J.-W. Tong, Y.-S. Gong, J.-A. Huang, and Z.-H. Liu, "Epigallocatechin-3-gallate promotes healthy lifespan through mitohormesis during early-to-mid adulthood in Caenorhabditis elegans," Redox Biology, vol. 14, pp. 305$315,2018$.

[93] D. Ryu, L. Mouchiroud, P. A. Andreux et al., "Urolithin A induces mitophagy and prolongs lifespan in C. elegans and increases muscle function in rodents," Nature Medicine, vol. 22, no. 8, pp. 879-888, 2016.

[94] J. Zheng, D. Heber, M. Wang et al., "Pomegranate juice and extract extended lifespan and reduced intestinal fat deposition in Caenorhabditis elegans," International Journal for Vitamin and Nutrition Research, vol. 87, no. 3-4, pp. 149-158, 2017.

[95] J.-H. Lee, S. H. Choi, O. S. Kwon et al., "Effects of ginsenosides, active ingredients of Panax ginseng, on development, growth, and life span of Caenorhabditis elegans," Biological and Pharmaceutical Bulletin, vol. 30, no. 11, pp. 2126-2134, 2007. 
[96] S. S. Smita, S. Raj Sammi, T. S. Laxman, R. S. Bhatta, and R. Pandey, "Shatavarin IV elicits lifespan extension and alleviates Parkinsonism in Caenorhabditis elegans," Free Radical Research, vol. 51, no. 11-12, pp. 954-969, 2017.

[97] J. M. Brimson, M. I. Prasanth, W. Plaingam, and T. Tencomnao, "Bacopa monnieri (L.) wettst. extract protects against glutamate toxicity and increases the longevity of Caenorhabditis elegans," Journal of Traditional and Complementary Medicine, 2019.

[98] C. Lin, Y. Lin, Y. Chen et al., "Effects of Momordica saponin extract on alleviating fat accumulation in Caenorhabditis elegans," Food \& Function, vol. 10, no. 6, pp. 3237-3251, 2019.

[99] M. Wink, "Evolutionary advantage and molecular modes of action of multi-component mixtures used in phytomedicine," Current Drug Metabolism, vol. 9, no. 10, pp. 996-1009, 2008. 